\title{
Colonización Fenicia de Occidente: La necesidad de una explicación Histórica Oriental ${ }^{1}$ Phoenician Colonization of the West. in need of an Eastern Historical Explanation
}

\author{
Francisco Gómez Toscano² \\ Universidad de Huelva
}

Recibido: 10-07-2013

Aceptado: 10-10-2007

\section{Resumen}

En la actualidad el paradigma de la Colonización Fenicia de Occidente sufre las consecuencias del paso del tiempo por los logros de la investigación, tanto a escala del Mediterráneo en general como de la Península Ibérica en particular. Con este trabajo se pretende concienciar de la necesidad de un cambio pero que sea coherente con el resultado de la investigación de los contextos histórico-arqueológicos actuales, lo que implica establecer una diferencia sustancial en la previa explicación de la evolución del proceso histórico en el Próximo Oriente, la cual también incide en la articulación protohistórica del extremo Occidente y, en especial, en qué se entiende en la actualidad por fenicios.

Palabras clave: Paradigma Colonización Fenicia Próximo Oriente Occidente Península lbérica.

\begin{abstract}
The paradigm of Phoenician Colonization of the West nowadays suffers the consequences of the passing of time due to the achievements of scientiphic research in the Mediterranean World and in particular in the Iberian Peninsula. In this paper we try to explain why to become aware of the real necessity to instrument an structural change with respect to new archaeological research results, which shall imply a substantial difference with eastern historical process as it was previously understood herein, that drastically emphasizes Far West protohistorical articulation and, specially, to substantiate who were historically the Phoenicians.
\end{abstract}

Keywords: Paradigm Phoenician Colonization Near East Far West Iberian Peninsula.

\footnotetext{
1 Dedicamos este trabajo al Dr. Manuel Bendala Galán ya que, por diferentes motivos, no tuvimos la oportunidad de colaborar en el homenaje oficial que le hizo esta revista. Este trabajo se inserta en el Proyecto de investigación 'Análisis de la implantación y evolución del fenómeno urbano en el Suroeste peninsular: Arqueología Urbana en la Ciudad de Huelva'. II ${ }^{\mathrm{a}}$ Fase" (Ministerio de Ciencia e Innovación. Ref HAR2008-04666-HIST) del Plan Nacional de I+D., así
}

como en el Proyecto Mission Archéologique de Tell Abu Hawam (MATAH), Maison de l'Orient et de la Méditerranée - Jean Pouilloux, (UMR 5649, C.N.R.S.) Université Lumiére Lyon 2.

2 fgomez@uhu.es Facultad de Humanidades. Avda. 3 de Agosto s/n. 21007 Huelva. 


\section{1.- LA COLONIZACIÓN FENICIA DE OCCIDENTE.}

La investigación de la Protohistoria en la Península Ibérica siempre ha estado vinculada a la explicación de dos tópicos interrelacionados: la paradigmática Colonización Fenicia de Occidente y la mítica ciudad de Tarteso. Como referencia o ejemplos a resaltar, si la evolución de la investigación puede seguirse a través de estudios con gran tradición del segundo de los tópicos realizado por J. Maluquer (1970) hace más de cuarenta años, el primero de ellos, para las investigaciones más antiguas, ha sido expuesto en la pasada década con dos trabajos por A. Mederos (2001; 2004), por J.L. López Castro (1992) desde su evolución conceptual a lo largo del siglo XX y, en general, en la introducción al tema en múltiples trabajos redactados por la mayor parte de los investigadores, como J.M ${ }^{\mathrm{a}}$ Blázquez (2005), que hace unos años expuso su personal forma de entender la evolución del concepto orientalizante en la investigación occidental. Por ello, si se quiere ampliar cómo se ha manifestado la evolución del conocimiento deberemos acudir a un número de obras tan ingente que por falta de espacio no podemos atender aquí de forma exhaustiva, aunque tampoco es el objeto de este trabajo.

Desde nuestro punto de vista y estimando el problema de la Protohistoria peninsular desde su vertiente histórico-arqueológica, parece interesante para entender lo reciente de esta aportación científica, que desde mediados del pasado siglo, como ya se vio en las conclusiones de la reunión celebrada en Jerez de la Frontera en 1968 (Maluquer, 1969), la mítica ciudad debía explicarse únicamente a partir de su excavación pormenorizada para, conociendo así su localización, sus arquitecturas y la cultura material específicas, podría ser mostrada sin las limitaciones que imponía la escasa calidad de los textos disponibles que la describían, que hasta entonces habían hecho que su deducción histórica divagara entre el mito y la realidad.

Como la ocasión era favorable en esos momentos, desde la década de los setenta y a partir de múltiples excavaciones que se llevaron a cabo en el espacio más meridional de Andalucía, los arqueólogos buscando a Tarteso descubrieron a los fenicios y su colonización (Gómez, 2013b, 290). Por ello, la Protohistoria, a partir del resultado obtenido en las primeras décadas de la segunda mitad del siglo, ya no será únicamente el resultado de la interpretación de las fuentes textuales históricas y la descripción de objetos obtenidos en hallazgos fortuitos relacionados especialmente con el mundo funerario como se había hecho hasta entonces, sino que ya se dispondrá de algunas estratigrafías que posibilitaron análisis comparativos de la evolución de la cultura material fenicia, en especial a partir de la publicación de la necrópolis de Laurita (Pellicer, 1962; 2007), donde fue fundamental la asociación de una kotila protocorintia y su copia eubea con otras cerámicas de engobe rojo, que servirían para establecer, por primera vez, un punto de partida de tipo cronológico relativamente seguro. Asimismo, la excavación de las colonias de la costa malagueña y la definición de sus cerámicas posibilitaron unas explicaciones que entonces parecían coherentes (Schubart, 1976; 1982a-b; 2005).

Hay que recordar que, para la sociedad occidental, las mismas estratigrafías, en la mayor parte de los casos, sobretodo en Andalucía Occidental, manifestaban la existencia de evidencias locales pertenecientes al final de la Edad del Bronce y su posterior convivencia con los materiales fenicios, hasta que el tratamiento a mano, por la influencia de las fabricaciones orientales, dejaba de ser la técnica local empleada en la manufactura de la cerámica que se utilizaría a partir de entonces. Una asociación bien conocida entre producciones locales e importaciones fue puesta de manifiesto en el Cabezo de San Pedro en Huelva, donde los niveles 6-5a y 5b, exclusivos de la Edad del Bronce, aparecían claramente separados del nivel 4 , en el que se mostraban las primeras cerámicas a torno (Blázquez et al., 1970), una circunstancia que se continua ignorando no sabemos por qué, pues, esos contextos, como ya hemos analizado en profundidad (Gómez y Fundoni, 2011; Gómez, 2013a-b), dejan en evidencia a aseveraciones que pretenden dejar sentado que el Bronce Final no es anterior al II Milenio en Huelva y en el Bajo Guadalquivir, solo para resaltar una presencia cananea-fenicia que, históricamente, al menos resulta extraña (Escacena, 2013).

Para entender las diferentes líneas explicativas de cómo se fue produciendo el conocimiento de los fenicios, habría, también, que detenerse en un ingente número de manifestaciones que debemos a un importante grupo de investigadores, que tampoco trataremos aquí de forma exhaustiva, sino que tan solo se harán unas puntualizaciones básicas generales. 
El conocimiento arqueológico de los fenicios en la década de los sesenta, estuvo basado en parte en la experiencia norteafricana de $\mathrm{M}$. Tarradell, el cual publicó, además del prólogo, una síntesis sobre los fenicios en Occidente incluida en la edición española del libro de D. Harden (Tarradell, 1967). Es interesante ahora observar, a pesar de lo que se diga categóricamente (Blázquez, 2002, 37), que sería el arqueólogo valenciano quién estableciera el concepto pre-colonial para explicar una primera etapa teórica de tanteo o exploraciones antes de la propia colonización del siglo VIII a.C., quizás para justificar de esa forma posibles hallazgos en Occidente de momentos previos y, así, confirmar la cronología de la fundación de Gadir por los tirios en el II Milenio a.C. si se seguía el texto de V. Patérculo (Tarradell, 1956, 794; 1967, 295) ${ }^{3}$.

Habría que resaltar que para establecer lógicos paralelos con la cultura material de la costa siropalestina, en esos momentos se contaba con la obra de R. Amiran (1969) y los trabajos previos de R. Saidah (1966; 1983), o estudios muy específicos (Olabarri, 1973), un bagaje realmente pobre ante la necesidad de reconocer esos paralelos, en especial para ajustar la cronología en general, de tal manera que, en poco tiempo, se conocería mejor a los fenicios en Occidente que en su país de origen (Aubet, 2006, 36). Sin embargo, ante la falta de trabajos relacionados con presupuestos teóricos y la disponibilidad de tipologías que mostraran la evolución de la cultura material de los fenicios en Occidente (López Castro, 1992; Martín Ruiz, 1995, 22), se prestó mucho más atención a los materiales peninsulares, pues así se evitaba tener que acudir a posturas incómodas por la dificultad de acceder al desarrollo de los fenicios en el Próximo Oriente, fundamentado, como se verá más adelante, en la interpretación de los datos arqueológicos pero siempre desde el paradigma bíblico.

En relación con esos presupuestos teóricos, J.L. López Castro destacó la propuesta de colonización agrícola de Whittaker (1974), que también sería objeto de estudio años después (Wagner y Alvar, 1989) y que ahora se discute (Almagro Gorbea, 2013, 491), o el modelo periférico depen-

3 El concepto se entiende también de forma bien diferente en la actualidad, como es explicado en profundidad por el Dr. Bendala en su relación con un Tarteso previo y ajeno a los fenicios, no por ello exento de contactos y relaciones orien- diente de Asiria de S. Frankenstein (1979), por el que los fenicios buscaban plata y otros productos en Occidente para su entrega a los asirios.

En la década siguiente van a ser importantes otras síntesis debidas a nuevas generaciones de arqueólogos, así como a la continua multiplicación de los datos de campo (Ruiz Mata, 1986). Una prueba de inmediatez a la hora de poder relacionar datos históricos con hallazgos arqueológicos puede extraerse del tiempo en que las cerámicas fenicias más típicas fueron descubiertas y entendidas en la Península Ibérica. Ya en la década de los años cincuenta, E. Cuadrado había comenzado a sistematizar las cerámicas de barniz rojo que documentaba en Murcia y que adscribía al mundo ibérico, cuando descubrió sus precedentes en ejemplos muy similares en los yacimientos fenicios más representativos, y de ahí interpretar su lógico origen y evolución cronológica (Cuadrado, 1953; 1969).

Las excavaciones analizadas en los sitios fenicios de la costa Sudeste de Andalucía aportaron, en esos momentos, las primeras tipologías de las cerámicas fenicias de engobe rojo, cuya evolución iría siendo confirmada en la mayor parte de los sitios excavados, convirtiéndose en un instrumento útil con el que establecer el tiempo de la colonización a partir de cambios formales (Schubart, 1976; 1982a; 1986b; 2005), que parecían tener su confirmación también en el Suroeste (Ruiz Mata, 1986).

Pero si hablamos del factor tiempo en relación con los navegantes que se han denominado fenicios a lo largo del siglo pasado, o mejor a su inclusión en un período histórico demasiado extenso que históricamente no les corresponde, basta observar cómo J.M. Blázquez, siguiendo a importantes autores del momento, también lo aplicaría a gentes de diferentes períodos (Blázquez, 1968, 32-58), tanto en el siglo VIII a.C. colonizando junto con los griegos el Mediterráneo Central siguiendo a R. Carpenter (1958), a los marinos de la costa siro-palestina en momentos cercanos al año 1000 a.C. en relación con el viaje de Unamón, o los de momentos muy anteriores de acuerdo con los textos de Ras Shamra (Blázquez, 1968, 35). Sin embargo, en su

tales previas, incluso con gentes del Egeo, que lógicamente recuerdan el ciclo de los nostoi, en especial por la procedencia de los materiales micénicos primero y de la génesis de algunos de los protofenicios después (Bendala, 2013). 
explicación, aunque los fenicios siguieran viejas rutas, el Dr. Blázquez entendía que la cronología de la fundación de Gadir obtenida a partir de V. Patérculo debía ser la que más se ajustara a la realidad, sin que debiera descartarse su adelanto en el Mediterráneo Central a los griegos, como estimaba Tucídides $(6,2,6)$ y confirmaba el bronce de Sciacca, en este caso al menos de los siglos XIV-XIII a.C. (Tusa, 1973, 177). Como es bien sabido y se ha repetido hasta la saciedad, el objeto de dicha presencia siempre fue estimado la búsqueda de metales (Blázquez, 1968, 45).

Más adelante, la década de los años ochenta va a ser fundamental por las nuevas aportaciones que llegarán a los investigadores occidentales, tanto las propias en la Península como las orientales, con trabajos de síntesis, revisiones y obras generales, fundamentadas en nuevas estratigrafías y tipologías de materiales que, en definitiva, podían haber significado la superación de viejas trabas, según se expuso en la reunión de Colonia organizada por H.G. Niemayer (1982a). Parece importante el conocimiento adquirido en la costa del Sureste peninsular, establecido a partir de trabajos del Instituto Arqueológico Alemán (Niemayer, 1982b; Schubart, 1982a), que ya permitía teorizar sobre la colonización (Del Olmo y Aubet, 1986), su plasmación en varias fases sucesivas a partir de Tiro (Schubart y Arteaga, 1986), o sobre el modelo de diáspora comercial de M.E. Aubet (1987).

Así, al final de esa década aparecerá la primera edición de la obra Tiro y las colonias fenicias de Occidente (Aubet, 1987), un trabajo bien fundamentado en la historiografía entonces disponible, que como referencia facilitó la labor de muchos al convertirse, prácticamente, en el manual a seguir para evitar adentrarse en obras de difícil acceso. Debemos comprender que la doctora Aubet, después de explicar exhaustivamente el origen de los términos cananeo, fenicio y púnico, entendía lógico seguir la práctica del momento, por lo que con el primero se designaba a una misma gente antes del 1200 a.C. y con el segundo los indicaba a partir de esa fecha. Para su presencia en Occidente, entre los siglos VIII-VI a.C., juzgaba que se debía utilizar el término fenicio occidental, ya que el tercero solo se utilizaría para nombrar a todos los demás en el conjunto mediterráneo pero ya a partir del siglo VI a.C. (Aubet, 1987, 11).
Entre algunos investigadores de la Península Ibérica, como ejemplo interesante de la última década del siglo XX, al mostrar la historiografía fenicia en relación con la investigación protohistórica, exclusivamente la occidental relacionada con las posturas teóricas e ideologías imperantes en los diversos paradigmas relacionados con la colonización fenicia de Occidente, como se quería poner el énfasis en la falta de explicación del hecho social siguiendo la moda anglosajona del momento, no se prestó cualquier atención al hecho histórico oriental, toda vez que, aparte de mencionar que ... hacia el 800-750 a. C., por consiguiente $^{4}$, los fenicios emplazaron sus asentamientos coloniales en las costas periféricas del mundo tartésico (Arteaga, 1995, 152), no se observa cualquier referencia o explicación de quiénes fueron, cuándo se puede llamar así a unos navegantes orientales específicos, o a qué tipo de sociedad representaban, como no fueran los actores de un estado más desarrollado y superior, ni realmente qué tipo de estado, como si en ese sentido todo estuviese dicho y demostrado y no hiciera falta cualquier puntualización aclaratoria más allá de ese ...por consiguiente.

Ello nos recuerda lo expresado por S. Moscati años antes en la introducción de su famoso Chi furono i Fenici? al reconocer que ...non vi sono tesi esposte ma teorie presupposte, che rendono il discorso ambiguo e la mutua compresione tra gli studiosi disagevole. Soprattuto, vi sono divergenze sulle origini del popolo e della cultura (Moscati, 1988, 24). Realmente, lo que se ha expresado en general hasta ahora, como base explicativa de la colonización fenicia de Occidente, en especial en lo que respecta a su origen y cronología, salvando alguna excepción, todavía hoy resulta un discurso ambiguo, estructurado desde presuposiciones obsoletas que desde el resultado de la investigación oriental no puede mantenerse por más tiempo, especialmente si se parte de las explicaciones simplistas o poco elaboradas tradicionales.

Contamos con muchos ejemplos concluyentes pues, recientemente, en una escueta introducción a la revisión de la Necrópolis Laurita que titula el territorio fenicio, M. Pellicer, uno de los mejores conocedores de la Protohistoria peninsular, comenta que ...entre estas ciudades será Tiro,

4 El resalte es nuestro. 
formando una asociación con su rival Sidón desde el s. XI, la principal protagonista de la colonización fenicia del Mediterráneo occidental $y$ del Atlántico próximo a las Columnas de Hércules, con la participación de Chipre (Pellicer, 2007, 33), y más adelante que la colonización ...fenicia de tipo permanente, del Mediterráneo Occidental, confirmada en el s. VIII, fue incentivada por razones económicas, como la adquisición de metales para su industria $y$ de alimentos para nutrir una superpoblación (Pellicer, 2007, 33). De alguna forma se resume así el parecer generalizado de los investigadores peninsulares en relación con los fenicios; si se nombra a Chipre es para evitar cualquier contingencia temporal determinada por la asociación fenicio-chipriota estimada por muchos desde momentos muy antiguos; también se menciona a la ciudad de Sidón que daría continuidad a la hegemonía tiria como se observa en los textos más tardíos y, lógicamente, se indica la búsqueda de metales para fundamentar por qué se produjeron las relaciones.

En nuestro caso, si queremos conocer el proceso histórico en general, todo ello nos lleva a revisar algunos conceptos, como la explicación del cambio de la Edad del Bronce a la Edad del Hierro en el Próximo Oriente, que si queremos entenderla desde Occidente, debe hacerse con modelos complejos. Para su papel en la Península Ibérica no basta adscribir a unos fenicios atemporales la responsabilidad de todos los cambios que se van a producir en la sociedad occidental (Gómez, 2013a), sin al menos decir quiénes eran, y si existieron otras posibilidades.

Como punto de partida, en este sentido y como veremos más adelante, los diferentes grupos sociales de la Edad del Hierro oriental no fueron exclusivamente la continuidad de los preexistentes en la Edad del Bronce, y si en algún caso hubo esa posible continuidad no resulta fácil seguirla ni a través de los textos ni con los datos arqueológicos actuales, a pesar de haber aumentado éstos considerablemente en los últimos años, sino que continuidad y/o cambio deben ser sopesados, delimitados y tenidos muy en cuenta.

Pero, si atendemos a lo publicado en relación con el proceso oriental en general y a los fenicios

5 Una explicación en parte diferente a la nuestra, basada fundamentalmente en los textos neoasirios disponibles, muestra en particular, está claro que nada parece complicado ni difícil de seguir a pesar de la falta de datos contrastables ${ }^{5}$. Frente a una descripción geográfica simple, con estados plenamente formados al parecer desde la Edad del Bronce, hoy se sabe que de la sociedad cananea multiétnica surgirán los reinos secundarios, pero solo a partir de los siglos X-VIII a.C. y no antes (Dever, 1992, 108; Joffe, 2002). En la actualidad, a grandes rasgos, en un complicado proceso de formación, sabemos cómo desde el siglo XI a.C., pero no de forma sincróni$\mathrm{ca}$, los cananeos de los centros urbanos se dispersarán entre los asentamientos menores; los pueblos del mar y sus descendientes se asentarán primero en la costa y después en el interior; aparecerán proto-israelitas de forma solapada en la frontera montañosa junto con otras tribus de pastores; en Transjordania surgirán los núcleos de los reinos amonitas, moabitas y edomitas; en Siria lo harán los futuros centros costeros que ahora denominamos fenicios, con los arameos más al interior y los neo-hititas en el norte (Dever, 1992, 108). En realidad un proceso muy complicado para ser entendido y explicado sin datos rigurosos.

En este sentido, en el caso que nos preocupa y en relación a cómo debemos entender a todos los niveles al mundo fenicio en particular, si seguimos como ejemplo de explicación a A.H. Joffe, que ya tiene más de diez años, ...Phoenicia was not a politically centralized state, nor an integrated ethnic group or nation. It was functionally interrelated by economics and many aspects of shared culture and language, but the city-states were not integrated politically and territorially (Joffe, 2002, 436). En efecto, todo parece muy diferente del mundo perfectamente estructurado y en paz que se desprende de las interpretaciones occidentales dadas por ahora, en las que, simplemente, los fenicios serían los descendientes de los antiguos cananeos y los púnicos su continuidad en el Mediterráneo a partir del ascenso político y económico de Cartago. Como si no hubiesen sucedido otras cosas dignas de atención y, además, sin atender a los cambios geopolíticos que se produjeron en estos siglos. En cuanto al nombre que utilizamos, debe quedar clara su ambigüedad (Bernardini, 2006, 197ss).

lo complicado de los procesos, puede verse en J.A. Belmonte (2007) 
Como es lógico, lo que surge de lo anterior es que este complejo mundo oriental que podemos considerar complicado desde un punto de vista poblacional, multiétnico y heterogéneo en particular (Faust, 2000), en el espacio temporal específico de los siglos XI-X a.C., bien conocido ahora en la Península por multitud de hallazgos orientales (Celestino, Rafel y Armada, 2008; Vilaça, 2013a-b), no puede explicarse desde reconstrucciones o modelos simples, sino a partir de planteamientos complejos de conjunto interrelacionados entre sí, siempre con el difícil pero digno de crédito apoyo de registros arqueológicos modernos y no exclusivamente con textos de dudosa credibilidad histórica, en especial por el momento en que fueron redactados, generalmente con la intención de resumir su historia. Además, como indica A.H. Joffe (2002), el desarrollo general deberá estar acompañado del específico de cada uno de los estados que denomina secundarios.

De la misma forma, tampoco podemos comparar a los orientales con el esquema de la sociedad occidental con que se contaba a mediados del siglo pasado. La cronología aplicada al final de la Edad del Bronce, con una horquilla estimada entre los siglos VIII al IX, si no era hasta el X a.C., de acuerdo con los hallazgos a torno del Cabezo de San Pedro fechados entonces no antes del 700 a.C. (Blázquez et al., 1970, 13), no puede seguir siendo utilizada ni manipulada, puesto que ni el análisis arqueológico (Gómez, 1998; 2006; 2008), ni las nuevas cronologías cronométricas, con ejemplos cercanos en la provincia de Huelva de los siglos XIV al IX a.C. (García y Hurtado, 2011; García y Odriozola, 2012, Tabla IV), en Medellín de los siglos XII al IX a.C. (Jiménez y Guerra, 2012, Tabla 1), en el Alentejo con fechas similares (Monge, 2005), y ahora también en El Carambolo, a pesar de lo que se diga, con la fecha más probable situada entre 1401 y 1131 a.C. (Fernández y Rodríguez, 2010, 215; Gómez, $2013,91)$, hacen el cambio necesario y pertinen$t^{6}$. Desde esta perspectiva, otros hallazgos en la Península Ibérica, como ejemplos, llevaron a estimar la presencia bien establecida de elementos orientales que ya no pueden ser adjudicados a los

6 A nosotros nos parece que es la cronología establecida hace más de cuarenta años la que todavía sirve para negar la existencia del final de la Edad del Bronce desde momentos anteriores al cambio de milenios, y no el registro arqueológico actual, como ha resultado ser en El Carambolo (Gómez, fenicios históricos, como el cuenco de Berzocana (Almagro, 1977, 243-245), los objetos de hierro de las Beiras (Vilaça, 2006; 2008; 2013a-b), los del tesoro de Villena (Lucas Pellicer, 1998), o uno de los útiles de la Ría de Huelva (Almagro, 1993).

Acercándonos a Oriente, en relación con la geografía fenicia, en el proceso histórico no está claro si las ciudades que determinamos fenicias localizadas al norte de la bahía de Haifa fueron grandemente afectadas por la presencia de los pueblos del mar a partir de la crisis del 1200 a.C., puesto que los textos no son concluyentes ni el registro arqueológico confirma qué pasó realmente durante los siglos XII-XI a.C., aunque algunos autores estiman que más que nuevas gentes lo que se produjo fue una reactivación del sustrato cananeo/fenicio (Gilboa, 2005, 51). ¿Pero sabemos cuando se indica ese sustrato de qué se está hablando? Resulta evidente, de acuerdo con la historiografía actual, que no se ha prestado atención al sujeto histórico más activo del proceso, puesto que, prácticamente, como durante los pasados siglos, desconocemos a qué y quiénes nos estamos refiriendo cuando hablamos de fenicios, tanto desde el conocimiento como lo contrario.

\section{2.- PROCESOS DE CAMBIO: LA NECESIDAD DE UNA EXPLICACIÓN DE ACUERDO CON EL REGISTRO ARQUEOLÓGICO MEDITERRÁNEO.}

Como contraste a la seguridad con que se interpretaba el siglo pasado la génesis y explicación del mundo fenicio, en estos primeros años del siglo XXI, como otro ejemplo reciente, debe tenerse en cuenta lo expresado por E. von Dongen pues, en relación con el conocimiento específico, incluso en manos de los especialistas, ...they... [los fenicios] ... are considered to have been an important factor in the history of the Mediterranean [pero, para] ...an outsider, this would suggest that it is quite well known who the Phoenicians were; but in fact, the material record is extremely scanty, extant written records are minimal and even their name is not indigenous (Dongen, 2010, 471).

2013a: 91, nota 21), donde ya es imposible negar la existencia de un asentamiento local previo a la construcción de un santuario de los siglos IX-VIII a.C. que no tiene precedentes en el mundo fenicio de esos siglos. 
Realmente, ante la escasa base con que realmente se cuenta, como solución a toda la problemática relacionada con navegantes o comerciantes atemporales, hemos propuesto que los fenicios en general, más que un proceso continuo realizado por gentes específicas procedentes de Fenicia (Dongen, 2010), la presencia oriental en Occidente debe dividirse en tres fases o períodos que se sucederían en el tiempo (Gómez, 2013a), por lo que no implica la existencia primero de una pre-colonización y a continuación la consiguiente fase colonizadora al modo egeo como para el Mediterráneo Central propuso en su día $\mathrm{S}$. Moscati (1983), o de forma parecida por M. Marazzi, como nos indicó M. Bendala hace unos años $(1992,377 ;$ 2013).

En los años noventa el descubrimiento de materiales a torno micénicos fue una revolución que produjo interesantes debates, e incluso se acusó de errores estratigráficos hasta que se dispuso de análisis de pasta que los acalló definitivamente (Martín de la Cruz, 1987; 1988; 2008). De acuerdo con el registro arqueológico que ahora debemos estimar, en la Península Ibérica, una fase previa, no demasiado bien definida por ahora dado la escasez de hallazgos, implica al comercio del mundo micénico en los siglos finales del II Milenio a.C. .; otra posterior, también con intereses puramente comerciales pero protagonizada por otros navegantes orientales de procedencia heterogénea, marcará la presencia de protofenicios durante los siglos XI-X a.C.; finalmente, la continuidad de la fase anterior puede estimarse a partir de comerciantes de Tiro pero solo desde los siglos IX-VIII a.C., a la cual siguió, como conclusión, la definitiva y verdadera colonización, en la que posiblemente participarían todos los asentamientos costeros orientales, ya que lo principal era encontrar tierras donde vivir tranquilos y a salvo del ejército asirio desde el tercer tercio del siglo VIII a.C.

Según se ha visto, puesto que partir de modelos simplistas no parece lo indicado, es lógico que se asuma entonces que el significado de la presencia sucesiva en Occidente de navegantes o comerciantes asimilados a los micénicos, continuada por protofenicios y fenicios desde el II

7 Esta probable presencia egea podría fundamentar también las referencias a los viajes de los nostoi como ha mantenido el Dr. Bendala durante las últimas décadas (Bendala, 2013),
Milenio a.C., cada uno en su momento, solo podrá explicarse y justificarse desde la Historia del Mediterráneo en general y de su sector oriental en particular. Todo estriba en plantear y concebir la evolución, el complicado proceso histórico experimentado por el mundo mediterráneo durante más de medio milenio, entre el final de la dominación egipcia de Canaán, tal vez a partir de Ramsés VI ca. 1135 a.C. y hasta las conquistas asirias del siglo VIII a.C. (Finkelstein, 1996, 179180), para entender que solo la revisión pormenorizada de cada uno de los casos -site to site- podrá llevar luz a la resolución de su modelo en particular, pues en contra de lo que antes se presuponía, posiblemente también pudo existir una mayor continuidad de la Edad del Bronce en el panorama de la consiguiente Edad del Hierro (Dever, 1992, 107-108).

Así pues, desde la evolución conocida de cada período y en cada espacio particular de la zona, entre otras cuestiones, se podrá explicar el cuándo, el por qué, y cómo tuvo lugar la presencia de qué navegantes orientales en las costas de la Península Ibérica y, asimismo, cuáles serían sus consecuencias, tanto para la sociedad local como también para los propios orientales. Aunque esta premisa no parezca demasiado importante para algún investigador, nosotros creemos que es imprescindible si lo que queremos es reconstruir la Historia del importante período en que la sociedad occidental se incorporó con pleno derecho al mundo mediterráneo, intentando siempre mantenernos lejos de implicaciones nacionalistas, provincianas, localistas, políticas o reivindicativas simplemente extrañas.

\section{1. ¿Es la Biblia la base empírica para recons- truir la Historia del Próximo Oriente?:}

Como presupuesto a estos planteamientos la respuesta depende de la línea explicativa de cada investigador. Debe tenerse en cuenta que hasta muy recientemente la Historia del Próximo Oriente más occidental en general ha estado impuesta por la lectura de los textos bíblicos, e incluso a lo largo de gran parte del pasado siglo $\mathrm{XX}$ los datos arqueológicos obtenidos sirvieron

o también las referencias previas a Crono y Briareo de las Columnas de Hércules que estimó el querido compañero Fernando López Pardo (2004). 
para confirmar las bases de dicha lectura y de su autentica explicación histórica. Como se ha afirmado, la arqueología en el Próximo Oriente se ha hecho con la ...bible and... [the] ...spade (Ussishkin, 2007, 132).

En lo fundamental, desde mediados del siglo, aunque existan claros precedentes por parte de otros investigadores de la American School fundada en Jerusalén durante el mandato británico que siguió a la Primera Guerra Mundial (Hallote, 2011, 167), la autoridad de W.A. Albright y sus seguidores (Feinman, 2004) impusieron sus tesis sobre otras posibles líneas de trabajo en su interpretación de la Historia del Próximo Oriente (Albright, 1941; 1942; 1946), y los datos arqueológicos de las excavaciones que se realizaron a partir de la creación del estado de Israel en sitios hegemónicos como Hazor, Megiddo, Gezer o Samaria, entre otros muchos, cumplieron en ese momento el papel de confirmarlo (Yadin, 1958; Yadin y Ben-Tor, 1993; Yadin et al., 1960). De esa forma, junto con los textos, la identificación de una arquitectura específica y la asignación a ella de una cultura material determinada, explicadas como el reflejo material del reino unificado de David y Salomón, han sido en general la única base empírica en vigor para concebir un proceso histórico que se ajustara escrupulosamente al texto bíblico.

Sin embargo, a lo largo de la segunda mitad del siglo XX, surgirán dudas lógicas y razonables fundamentadas ahora en el registro arqueológico. Entendiendo como un todo el espacio comprendido entre Gaza al sur y la bahía de Haifa al norte, en el actual estado de Israel, el análisis combinado del texto bíblico y el resultado de la investigación arqueológica de campo habían fechado fácilmente la ocupación salomónica del siglo $\mathrm{X}$ por un lado y la del reino dividido en el siglo VIII a.C. por otro, pero, con ello, surgían dudas difícilmente superables al partir del análisis del registro arqueológico disponible si se aislaba del hecho textual asumido en general como cierto e incuestionable.

En el reino sur, como se sabe menos poblado que el norte, al haber partido igualmente de destrucciones asignadas a diferentes conquistadores y las naturales reconstrucciones basadas en la

8 En general, cuando se menciona una cronología contrapuesta a la tradicional, el principal referente para la denominada
Biblia que significaban la continuidad de los sitios (Herrera y Gómez, 2004, 161), en comparación con los materiales de la zona norte, para el siglo IX situado entre ellos no hubo modo de establecer una evolución material similar como no fuera con la comparación de estratigrafías poco precisas o de muy poca entidad, como si no hubiese existido nada relevante durante ese siglo IX a.C. (Finkelstein, 1996, 181), o quizá, lógicamente, como si todo estuviese fundamentado en un error interpretativo impuesto claro está por la cronología bíblica tradicional, porque considerar que la cultura material habría variado poco durante todo un siglo, o sería similar a la anterior, no puede llevar a una solución razonable (Mazar, 2011).

Así, en el reino de Judá, de acuerdo con la low chronology recién acuñada ${ }^{8}$ como crítica a la tradicionalmente establecida y con los datos arqueológicos del momento, en especial por el resultado de análisis radiocarbónicos y un diagnóstico integrado a escala territorial, las primeras fortificaciones de envergadura conocidas no serían anteriores a la segunda mitad del siglo IX a.C., y por ello claramente posteriores al bíblico reino unificado (Finkelstein, 2012). El resto serían asentamientos de poca entidad.

En la zona montañosa, donde Jerusalén debería ser un punto idóneo donde fijar la evolución del reino y su continuidad (Na'aman, 1996; Schniedewind, 2003, 379; Cahill, 2003), aún hoy parece difícil establecer qué representaría a la capital de David y Salomón durante el siglo X a.C. (Vaughn y Killebrew, 2003), porque cualquier estructura monumental, o de cierta relevancia, que fuese posterior a la ya conocida fortificación de la Edad del Bronce, a la larga ha resultado ser más tardía que la fundación de Samaria por Omri (Finkelstein, 2001; 2006; 2008; 2011a; Finkelstein, Koch y Lipschits, 2011), o al menos existen dudas razonables para asignar las descubiertas directamente a mediados del siglo X a.C.

De cualquier forma, mientras que unos esperan encontrar cualquier día evidencias de la ciudad monumental que debió existir durante el reino unificado según los textos, otros muchos como D. Ussishkin asumen la realidad arqueológica actual (Ussishkin, 2007, 134), y entiende que entre las

low chronology es el profesor Israel Finkelstein, de la Universidad de Tel Avid. 
conocidas fortificaciones de la Edad del Bronce y la del siglo VIII a.C. no existió la que se ha deducido debería ser localizada allí (Ussishkin, 2012, 108). En este sentido parece interesante el reciente debate suscitado en torno a los últimos hallazgos fruto de excavaciones realizadas en Jerusalén por E. Mazar, con el hallazgo y nueva interpretación de estructuras de grandes bloques o tramos escalonados relacionados con la ciudad salomónica (Mazar, 2009; Faust, 2010, lám. 23, A), que de acuerdo con los materiales asociados realmente han sido estimadas de varios momentos por diversos investigadores, lo cual no aclara demasiado y de forma fidedigna las características de la ciudad del siglo X a.C., por lo menos su esperada monumentalidad de acuerdo con Reyes I, 9, 15 (Steiner, 2003, 351ss; Mazar, 2006, 256; Finkelstein et al., 2007; Finkelstein, 2011a).

Finalmente, para el territorio incluido en el reino norte, mucho más rico y productivo en cuanto a recursos que los anteriores, los puntos principales de discusión serían Megiddo y Jezreel, ocupados desde la Edad del Bronce (Finkelstein, 1996, 182), por lo que para los siglos X-VIII a.C. también se debería contar con una cultura material y una arquitectura específica equiparable con las de otras zonas del país. Hasta ahora las dudas son razonables, por lo que no existe unanimidad en el conjunto de las interpretaciones que se barajan.

\subsection{Novedades en la investigación arqueológi- ca de campo y resultado de los análisis crono- métricos:}

Un ejemplo claro de las vicisitudes por las que lógicamente ha pasado la interpretación bíblica de la zona se observa en Tell Abu Hawam, en la bahía de Haifa resguardada por su localización al pie del monte Carmelo, punto bisagra entre Fenicia y Palestina (Herrera y Gómez, 2004). Excavado en dos campañas de verano en los años 1932 y 1933 durante el Mandato Británico, R.W. Hamilton (1935) propuso que un estrato de incendio que él creía generalizado habría destruido completamente el pequeño puerto fortificado, dando lugar a su abandono hasta el período persa. De acuerdo con el conocimiento del momento, la destrucción se adscribió a la campaña de Sheshonq I, estimada ca. 925-918 a.C., que tendría que ser el Shishak bíblico (Hamilton, 1935; Herrera y Balensi, 1986; Herrera y Gómez, 2004, 161).
Para W.F. Albright (1943), el final de Tell Abu Hawam debía ser anterior a Megiddo V, una cronología que ahora, como es lógico, se discute, pero la cultura material del incendio sería inmediatamente posterior al reinado de Salomón. Con el tiempo, pasando por diferentes críticas y nuevas propuestas planteadas por diversos investigadores (Herrera y Gómez, 2004, 29-32), el desarrollo de la investigación del puerto ha permitido establecer un punto de partida mucho más claro y coherente, y por ello determinar la cronología de los materiales amortizados por su destrucción en comparación con los conocidos en otros sitios. La presencia de cerámicas egeas del MGII e, incluso, de su transición al $L G$ en el contexto del potente incendio (Gómez y Balensi, 1999), junto con la identificación de cerámicas locales, especialmente las de engobe rojo bruñido y otras bícromas, permiten entender que esa gran destrucción debió ser posterior a mediados del siglo VIII a.C. pero anterior al último cuarto del mismo siglo, que nos ha llevado a relacionarla con a la campaña punitiva asiria de Tiglath Pileser III, estimada $c a$. 733732 a.C., prácticamente dos siglos después de lo apreciado a comienzos del pasado siglo por R.W. Hamilton, un hecho importante porque Tell Abu Hawam es uno de los sitios que había servido para mantener la credibilidad bíblica.

Otro ejemplo que puede llevar a confusiones es estimar que el reino de Ugarit pueda considerarse un centro cananeo-fenicio donde establecer generalmente paralelos con los de la sociedad fenicia de la Edad del Hierro, bien con arquitecturas o incluso con sus dioses más típicos como Baal, a pesar de sus contactos con Biblos, Tiro y Sidón, centros que en momentos previos a la desaparición de Ugarit se encontraban bajo el poder o la hegemonía de Egipto. Lo que muestran las excavaciones es que la ciudad fue destruida $y$ abandonada a partir de $c a .1195-1185$ a.C., y los Shiqala responsables de esa destrucción no se asentaron en ella, sino que el lugar no volvió a ser ocupado durante siglos (Yon, 1992, 120), por lo que no se puede garantizar su continuidad con el mundo fenicio de la Edad del Hierro.

En general, para todo Israel, la adscripción de arquitecturas y cultura material concretas al reinado de Salomón, sin otra base que lo que podía deducirse del relato bíblico, ya no puede mantenerse, en especial por las revisiones arqueológicas de conjunto realizadas en el territorio y el resultado de los mencionados análisis radiocarbónicos, 
que indican que lo anteriormente considerado salomónico debe rebajarse al menos en un siglo. La Biblia, en realidad, es fundamentalmente un texto religioso que no debe entenderse como una verdadera recreación histórica, o que al menos no se redactó con esa intención. Lo principal ahora, aunque el debate no es nuevo (Kenyon, 1964), es que las grandes fortificaciones que se relacionaron en su día con el rey Salomón, como los ejemplos de Megiddo y Gezer en el norte o Beer-sheba y Lachish, deben corresponder al siglo IX a.C. o, incluso, ser posteriores, pues tal vez deban conectarse a sus complejas fortificaciones edificadas con técnicas comunes o similares del tiempo de la confrontación expansiva aramea protagonizada por el rey Hazael de Damasco en el último tercio de ese siglo y/o la amenaza asiria del siguiente (Finkelstein, 1996, 185), la cual alcanzaría una gran importancia hasta hacerse traumática en el último tercio del siglo VIII a.C. (Liverani, 1991).

Si a ello unimos que la problemática identificación del bíblico Shishak con el faraón Sheshonq I de la Dinastía 22, que en el texto asoló Jerusalén en el 925 a.C. algo después de la muerte de Salomón, sea el único anclaje histórico entre la descripción bíblica y la cronología egipcia, un episodio basado meramente en la similitud de los nombres, se trata de una posibilidad no aceptada por todos los investigadores (James, Kokkinos y Thorpe, 1987, 33-34), que descuadra todo el sistema, en especial por la más reciente problemática arqueológica que suscita esa campaña punitiva en el reino de Judá, donde faltan las lógicas huellas físicas del conflicto (Finkelstein y Piasetzky, 2006; Fantalkin y Finkelstein, 2006). Téngase en cuenta que el fragmento de estela de Megiddo con la cartela de Sheshonk documentado en superficie en 1926, aunque en su día se asignó al estrato IV (Chapman, 2009), no puede relacionarse realmente con el siglo X a.C., y por ello su relación con una cultura material y una arquitectura específica debe incluirse en el afán probativo del texto bíblico, pero para seguir los esquemas tradicionales.

Por todo ello, de acuerdo con la low chronology de I. Finkelstein (2011b), como resultado del cambio en la interpretación histórica de los datos arqueológicos, la evolución material de la Edad del Hierro en el reino de Israel debe ser considerada, de forma simplificada, en tres amplios períodos:

a) Lo anterior al reinado de Omri, donde no tendría cabida el reino bíblico unificado por David y Salomón; b) La continuidad de la dinastía del monarca samaritano en representación de uno de los primeros reinos de la Edad del Hierro en el país;

c) Su expansión en la primera mitad del siglo VIII a.C. previa a las conquistas de Tiglath Pileser III, Salmanasar V, Sargón II y Senaquerib en el último cuarto de ese siglo.

Aunque en algún caso se pida un consenso que todavía implica la primacía de los textos (Bodine, 2010), desde luego, estas revisiones están siendo contestadas por investigadores maximalistas que, partiendo de un inmensa lista de referencias, especialmente de base religiosa, que no vamos a recoger aquí simplemente por falta de espacio, consideran los textos bíblicos realmente históricos (Mazar, 2005; 2010; 2011) y además sujetos puntualmente a la cronología de $\mathrm{C}_{14}$ (van der Plicht, Bruins y Nijboer, 2009; Bruins, Nijboer y van der Plicht, 2011). También existen posturas intermedias que no pueden ser una solución (Herzog y Singer-Avitz, 2004) pero, afortunadamente, del debate tienen que surgir mejores planteamientos y un nuevo instrumento con el que plantear una fundada reconstrucción histórica como la que todos debemos pretender y desear.

Por ello, es evidente que la reconstrucción histórica de los reinos de Israel y de Judá que proponemos, teniendo en cuenta o no el texto bíblico, deberá estar basada en el registro arqueológico de los cuatro puntos clave de Megiddo, Lachish, Jerusalén y Samaria (Ussishkin, 2007, 135), pero adaptando al esquema resultante el de otros sitios, pues no solo deberá utilizarse el de esos cuatro principales. Ello tendrá que redundar en la explicación del proceso en el Próximo Oriente a lo largo del I Milenio a.C., en el desarrollo de la Protohistoria del Mediterráneo en general y, lógicamente, también en el de la Península Ibérica.

\section{3.- DE ORIENTALES EN GENERAL A FENICIOS EN PARTICULAR:}

Tal como se ha visto en páginas precedentes, el dilema consiste en que, durante los años setenta y ochenta, parecía que se confirmaba el paradigma bíblico. Además, fueron muy importantes algunas excavaciones realizadas y publicadas, para, desde el registro arqueológico, manejar el paralelismo de la cultura material israelita, teóricamente muy bien fechada a través del texto bíblico y la arquitectura excavada en los grandes asen- 
tamientos salomónicos, así como estudios cerámicos específicos que hicieron posible la tipificación y distribución de las cerámicas chipriotas, chipro-fenicias y fenicias en general, con lo cual se había ido construyendo un modelo común para todo el mediterráneo, desde las cerámicas bícromas, las Black-on-Red o las de engobe rojo bruñido más típicas asignadas al mundo fenicio o chipriota. Entre ellos debemos incluir Tel Mevorak, donde se intentaba corregir la cronología baja de Gjerstad (1948; 1960), para llevar todo o parte del conjunto excavado al siglo $\mathrm{X}$ a.C. (Stern, 1978, 62).

De la misma forma, al final de la década de los setenta ya estaría disponible la primera estratigrafía de Tiro (Bikai, 1978), que se reconoce no aporta cualquier novedad histórica y por ello se asume la explicación de la historia del puerto resuelta por H.J. Katzenstein (1973). También, muy pronto, se conocieron las de Sarepta (Chapman, 1972; Anderson, 1981; Pritchard, 1983; 1988), o Tel Keisan (Briend y Humbert, 1980; Humbert, 1981), que aportarían la evolución de las cerámicas tirias durante la Edad del Hierro, para fijar a partir de ellas con mayor precisión las importaciones fenicias en la Península Ibérica, especialmente desde el estudio de las localizadas en Chipre, en este caso por contarse allí con formas completas (Bikai, 1987a), especialmente en necrópolis (Culican, 1982, 46).

Para el Próximo Oriente mediterráneo, el final de la Edad del Bronce, incluyendo los momentos previos a la crisis de 1200 a.C., no está suficientemente establecido, precisamente por la posible heterogeneidad de las causas que dieron lugar a tales convulsiones, sociales, políticas, económicas o tecnológicas que podrían explicar su generalizada dimensión. Es fundamental que desde el punto de vista de las relaciones comerciales, con el resultado de la crisis culminase la hegemonía micénica del comercio internacional mediterráneo de tipo aristocrático basado en productos apreciados por su valor intrínseco, como esclavos y metales entre otros (Aubet, 2003, 96).

Para una explicación del contexto histórico en los momentos previos podemos volver a Tell Abu Hawam, pues para la presencia micénica en la costa siro-palestina, el pequeño puerto continúa siendo un punto de referencia desde su excavación por R.W. Hamilton (Balensi, 1980; 1985; 1988; 2004). Su posición en la costa junto al monte Carmelo, en la misma equidistancia con
Egipto y Chipre, por sus importaciones ...inhabituelles en quantité et variété : céramiques peintes, figurines de terre cuite, sceau en verre, signes chypro-minoens, ambre de la Baltique (Balensi, 2004, 162), no tienen otra explicación que se interprete al sitio como ...un comptoir, pour des marchands mycéniens opérant dans le Levant sud (Balensi, 2004, 162), es decir, un punto principal del momento en que se documenta la interrelación entre el Egeo, Chipre, la costa siro-palestina y el país del Nilo previo a la crisis del 1200 a.C., imprescindible para explicar los mecanismos del comercio de la Edad del Bronce en el conjunto del Próximo Oriente mediterráneo.

Desde sus comienzos hay que explicarlo como centro de influencia en Canaán, tal vez una fundación egipcia que para ello acondicionó la isla o barra arenosa, que pronto recibió un aporte de población del norte levantino y de Chipre; predominio de cerámicas chipriotas e indiscutible presencia de materiales egeos datados en el período MIII A2 y MIII B1, que más tarde serán sustituidos por tipos levanto-micénicos o chipro-micénicos; destrucción de sus fortificaciones por los pueblos del mar; abandono circunstancial pero con continuidad a lo largo de la Edad del Hierro (Balensi, Herrera y Artzy, 1993; Balensi, 2004, 162-163; Herrera y Gómez, 2004), al menos hasta finales del siglo VIII a.C. Todo ello convierte a la historia de este antiguo puerto de la bahía de Haifa en la explicación del proceso histórico en este punto central del mundo oriental que estudiamos, localizado a socaire del Monte Carmelo. La historia de Tell Abu Hawam es, pues, la de la costa siro-palestina, si la situamos entre la Edad del Bronce y la del Hierro.

Para los inicios de la segunda fase en la Edad del Hierro, como se ha visto más arriba, la falta de textos contemporáneos o ligeramente posteriores a la crisis generalizada dota al episodio del funcionario egipcio Unamón, al fecharse en torno a 1075/1065 a.C. (Galán, 2000, 181; Aubet, 2009, 29), de una gran importancia para poder entender quiénes fueron los navegantes de los siglos XI-X a.C. que dieran continuidad a los comerciantes micénicos de la Edad del Bronce (Aubet, 1987; Egbert, 1991), tanto en el entorno oriental como en el Mediterráneo central e, incluso, en el extremo Occidente que precedieron a la paradigmática colonización fenicia.

En efecto; para la reconstrucción histórica del Próximo Oriente en particular es fundamental reconocer el cambio producido por la crisis de 
finales del II Milenio a.C., pues parece que ésta fue algo más que una explicación consensuada de la transición entre la Edad del Bronce y la Edad del Hierro (Ward y Joukowsky, 1992; Gitin, Mazar y Stern, 1998). La modificación desde formas de escritura complicadas al uso del alfabeto; la caída de antiguas ciudades-estado basadas en la agricultura y en los recursos del entorno; el nacimiento o la aparición de nuevos imperios que condenarían durante siglos a la dependencia económica de minorías y mayorías más débiles; el cambio de tecnologías, como la generalización del uso del hierro, y lo que ello conlleva no son más que las novedades o las reformas más aparentes. También, la definición de nuevas gentes que se integran en el tejido poblacional que se vienen asociando a los pueblos del mar, desde los peleset (Kahn, 2011, 4-5) a los shardana (Jeffrey, 2013), esté o no clara su procedencia externa, su pertenencia a grupos de guerreros especializados, a raza, etnia o, simplemente, a grupo homogéneo entendido con posterioridad como independiente de otros semejantes, o tal vez incluso de un país o de un territorio europeo septentrional que ya no se sustenta.

No existe demasiado consenso en cuanto a que se cuente con una cronología ajustada y generalizada de todos los cambios, sino que en unas áreas esos cambios se experimentan en momentos diferentes al que en otras. Sin embargo, actualmente se cuenta con opiniones que difieren en que no deben achacarse a las consecuencias de grandes movimientos en masa de gentes a la búsqueda de alimentos, riqueza o pillaje, relacionadas claro está con su génesis, circunstancia o procedencia. Esos movimientos sí existieron, como no se ponía en duda a principios del siglo pasado, pero ahora se piensa que más bien fueron transformaciones estructurales relacionadas con el comercio profesional oportunista (Aubet, 2003), no estatal, y a qué ocurrió en cada caso, seguramente antes y después de las invasiones o movimientos circunstanciales de gente armada debidas a múltiples causas.

De forma particular, si en el mundo micénico previo se habían impuesto los poderes palaciales locales a escala global, como ejemplo, frente a piratas, mercenarios y masas necesitadas debido a catástrofes naturales o provocadas por un agente específico, como en Chipre no se había mantenido anteriormente un poder semejante en su conjunto (Knapp, 2009, 222; Leriou, 2011, 264), durante los siglos XI-X a.C. comerciantes emprendedores de diversa procedencia que experimentaban con nuevos mercados y con nuevas mercancías darían los primeros pasos hacia un nuevo futuro: la Edad del Hierro (Muhly, 1992, 19). En ese proceso, otros centros sucederán al de Enkomi y se convertirán en los principales benefactores de la industria del cobre local y el procedente de diferentes zonas mineras mediterráneas importado en la isla (Stos-Gale y Gale, 2010, 400), regentada esa industria tal vez a partir del aporte egeo de los recién llegados (Karageorghis, 2002; 2005), aunque de forma diferente a cómo se había hecho hasta entonces a escala mediterránea.

A escala del Próximo Oriente, incluyendo a Chipre, frente a pequeñas ciudades-estado más o menos hegemónicas, lo beneficioso para todos es que los grandes imperios no volverán a tener la importancia coercitiva anterior. El imperio hitita, que en el II Milenio había disputado a Egipto su preponderancia en la zona, desaparece para siempre de la escena (Güterbock, 1992, 55); el imperio egipcio, la caña cascada con la que se comparará desde entonces, se enclaustrará en su frontera del delta del Nilo y también desaparecerá de la escena política durante varios siglos, al haber perdido su preeminencia anterior como puede verse en la actitud de Zacarbaal con Unamón (Aubet, 1987, 303). Así, libres de su presión, una de las consecuencias del cambio entre los siglos XII y X a.C. será mayor libertad de los habitantes de toda la zona para crecer en todos los sentidos, al no tener que sufrir grandes limitaciones impuestas por las armas como en momentos previos. En esa explicación, frente a otras ya obsoletas, los Pueblos del Mar según S. Sherratt, podrían explicarse como .... a structural phenomenon, a product of the natural evolution and expansion of international trade in the $3 \mathrm{rd}$ and early 2nd millennium, which carried within it the seeds of the subversion of the palace-based command economies which had initiated such trade in the first place (Sherratt, 1998, 294). Nada que ver con la interpretación difusionista-colonialista europea de los siglos XIX al XX.

La continuidad del fenómeno puede observarse en el panorama que aparece en el texto del viaje del egipcio Unamón, incompleto y cuya redacción puede ser más tardía de la fecha en que se desprende tuvo lugar (Sass, 2002). Como se describen las peripecias de un enviado de Ramsés XI (ca. 1100-1070 a.C.), el último faraón de la 
Dinastía XX, a la costa siro-palestina para obtener madera de cedro, este texto representa en la práctica la única referencia de la costa manejable para el investigador actual. El escenario político y económico que se observa parece concluyente; se menciona a comerciantes con base en diferentes puertos y además de en el de Dor se cuentan veinte barcos en Biblos, cincuenta en Sidón, once de los Tjekker en el mar que perseguían al egipcio, así como diez de la reina chipriota de Alasiya donde el enviado del faraón había recalado de vuelta a su país de origen siguiendo la ruta natural desde la costa siro-palestina. Estos navegantes y sus barcos, que no serían únicamente los nombrados, como ejemplo de otros muchos procedentes de diversos puertos, no parecen corresponder a una etnia específica, sino que en general son habitantes heterogéneos con base en los puertos de la costa, incluidas Chipre y tal vez Creta, cuando aún no se han forjado los estados étnicos secundarios o las ciudades-estado de la Edad del Hierro, que como se estima solo lo harán con posterioridad (Joffe, 2002).

Son los descendientes de ese convulso mundo que se gestó a partir de la mencionada crisis, que implica la continuidad de los comerciantes mediterráneos del período micénico, no solo egeos, sino también de parte de los pueblos del mar y de los primitivos habitantes de Canaán (Tsirkin, 2001), el teórico territorio situado al norte de Egipto en la franja costera, las actuales Palestina, Israel y Líbano, donde a lo largo de los siglos XIX a.C., como se ha mencionado, se fueron conformando los estados de Israel y de Judá, pero también al interior el de los amonitas, moabitas, edomitas, las ciudades filisteas más al sur y los puertos de Tiro y otras ciudades-estado independientes más al norte, aquellas que se ha convenido en llamar fenicias siguiendo a autores muy tardíos con respecto a los hechos que se comentan.

Ello implica, si atendemos a lo que se ha deducido de la información más creíble con que se cuenta, que primero se conformaron los estados de la Edad del Hierro y que con posterioridad se acuñó su denominación étnica o histórica, aunque los textos no hagan distinción de cuándo podamos definirlos ya como etnias consolidadas y con un nombre histórico concreto. Es decir, no solo los fenicios serían antiguos cananeos como suele afirmarse sin cualquier debate, prejuicio o desconocimiento, sino también los hebreos, parte de los filisteos junto con emigrantes postmicénicos del momento procedentes en principio de los puertos chipriotas o directamente del Egeo (Dothan, 1992; Hadjisavvas, 2007), así como gentes de otros de los estados antes mencionados. En realidad, todos los que habitaban en un territorio mal definido pero situado al norte de Egipto (Röllig, 1983), para cuya génesis no se cuenta, ni se contará seguramente, con el suficiente consenso entre los investigadores que estudian el caso (Röllig, 1995, 214).

De forma particular, entre los denominados pueblos del mar que aparecen asentados en la costa siro-palestina, siguiendo el texto de Unamón, de norte a sur, en la línea costera desde el siglo XI a.C. estarían los asentamientos de los shardanaltjekker, shekelets y filisteos (Gilboa, 2005, 47). En el caso de Dor, mientras que para algunos autores sería el principal asentamiento de los shekelets para convertirse después en un puerto fenicio, también implica continuidad de población entre los siglos XI-X a.C., pues aquí los fenicios posteriores serían antiguos shekelets no cananeos (Gilboa, 2007, 211), una circunstancia que no nos permitirá concretar en la descendencia exclusiva de los fenicios históricos solo desde los cananeos. Sin embargo, la diferencia está en que esos pueblos del mar pudieron haber estado ya en Dor incluso desde la Edad del Bronce, como gente local cananea, ya que lo contrario solo se desprende de la mención de shekelets residentes allí en el texto egipcio de Unamón (Sharon y Gilboa, 2013, 464), aunque solo podrían ser un grupo, o quizá una de las clases sociales o gentes del mar que circunstancialmente lo habitaban o utilizaban como base de su comercio oportunista.

Por lo tanto, la cuestión es qué debemos entender conformó a la población de la Edad del Hierro en la costa sirio-palestina en particular y qué podemos establecer surgió de la continuidad o de la renovación debida al movimiento de gentes heterogéneas durante la crisis del 1200 a.C. Desde este punto de vista donde prima la heterogeneidad de las gentes de la zona y la escasez de datos fiables, debe entenderse la puntual referencia a Fenkhu y Hau-nebut en Medinet Abu como enemigos asiáticos que se han relacionado con fenicios (Bikai, 1989, 135), o también de los Habiru o Hapiru, tal vez un apelativo relacionado con hebreos problemáticos acusados de rebeldes, o quizá también una clase social de gentes que habitaban al norte de Egipto y no una etnia propiamente dicha, o únicamente un nombre previo o 
diferente al de hebreo, ya que este último puede relacionarse con los que están lejos de su país (Na'aman, 1986, 288).

Por todo ello, para los protagonistas de la colonización fenicia de Occidente, el hecho es que, como los datos empíricos no son concluyentes, deberíamos ser prudentes y elaborar hipótesis de trabajo y esperar su contrastación con datos empíricos, en especial lo que pueda explicar quiénes fueron realmente los responsables de la colonización histórica del siglo VIII a.C. y, principalmente, reconocer a los fenicios en un tiempo específico y en el espacio mediterráneo concreto. Así, deberá especificarse con claridad cuáles fueron sus precedentes desde la Edad del Bronce, cuándo desarrollaron el concepto de pueblo o de país, de nación, de estado, o simplemente de grupo independiente o diferenciado de sus vecinos, si es que alguna vez ellos se consideraron así, algo más que ciudades-estado independientes por definición. De ellos se ha dicho que se reconocían simplemente ...collectively-first and foremost as cna'ani (Sherratt, 1998, 307). También será importante conocer por qué comenzó su expansión mediterránea, lo cual coadyuvaría a establecer una solución relacionada y clara de cuándo comenzó esa expansión.

Pero si nos preguntamos quiénes eran realmente los fenicios de la Edad del Hierro, la respuesta tiene que surgir del conocimiento actual y no como se ha hecho hasta ahora partiendo de textos tardíos, aunque sea necesario un breve repaso de la historiografía, que tampoco puede ser exhaustivo aquí por las limitaciones de este trabajo, sino simplemente para tener en cuenta la tradición investigadora como una referencia al hecho científico, o tal vez para indicar la existencia de diferentes interpretaciones de unos mismos datos, que deben incidir en nuestra percepción actual.

En cuanto a la cuestión anterior de quiénes eran los fenicios y si descendían realmente de los cananeos, las más antiguas referencia a Canaán y los cananeos aparecen en el siglo XIV a.C. en las Cartas del Amarna (Sparks, 1998, 98), que han sido seguidas por la mayoría de los investigadores, aunque lo único que se pueda decir de Canaán es que teóricamente era una posesión egipcia no bien definida al norte del delta, nunca como un país habitado por una étnica específica, la cananea. Desde un punto de vista histórico, como ejemplo, según O. Negbi (1992), la historia de los fenicios comenzaría en el cananeo Sidón, pues en
Homero se les llama sidonios, con lo que serían descendientes directos de los cananeos. No obstante, no todo parece tan claro y tan simple, pues las opiniones son muy variadas.

Remontándonos a fines del siglo XIX, siguiendo los esquemas de su época a través de los textos, para G. Rawlinson los fenicios serían uno más de los pueblos descendientes de Sem, como los asirios, babilonios, arameos o sirios, árabes, moabitas y hebreos, y las estrechez de su país la causa que les impulsó a navegar y colonizar parte del mundo de su época (Rawlinson, 1889, 17-30). Más tarde, ya en las primeras décadas del siglo pasado, W.C. Fleming, además de aportar la bibliografía existente hasta el momento, en su History of Tyre entiende que la historia de Fenicia es la de sus ciudades-estado independientes, las cuales nunca buscaron poder político sino económico, y deduce que ...It is clear from the language of the Phoenicians that they were Semites, and were related to the Assyrians, the Babylonians, the Arabs, and especially to the Hebrews (Fleming, 1915, 1), aunque se ve con claridad que todo el discurso depende de la interpretación de los textos, especialmente el bíblico.

Estas interpretaciones se van consolidando hasta mediados del siglo XX. Para B. Maisler (1946), siguiendo a Filón de Biblos, los fenicios serían la continuidad de los míticos cananeos y Canaán el país de los mercaderes orientales. También D. Baramki (1961) estima que los fenicios fueron la fusión de algunos de los pueblos del mar asentados entre los cananeos. En el caso de D. Harden (1967, 26-29), que amplía su explicación, admira el impacto causado en la historia mundial y en el desarrollo de la cultura, pues los fenicios, que tal vez llegaron a Canaán procedentes del Golfo Pérsico durante la Edad del Bronce, serán el resultado de la evolución posterior a la crisis del 1200 a.C., puesto que los navegantes de Tiro se verían preparados y a salvo en su isla para hegemonizar el comercio en general, pues fue ...entonces cuando Egipto entró en un largo período de decadencia; el imperio hitita fue destruido; Asiria comenzaba a convertirse en una potencia mundial, y los micénicos habían sido conquistados en su tierra de origen por los invasores del Norte (Harden, 1967, 58). Su fin llegaría en Oriente en el siglo IV a.C. con Alejandro para los fenicios y en el 146 a.C. en Occidente con la toma de Cartago por Roma (Harden, 1967, 29). 
En estas revisiones, los típicos términos geopolíticos de Canaán, de Fenicia, o también el de la púrpura, fueron discutidos por M.C. Astour y su relación con la presencia fenicia en el Egeo (Astour, 1965, 346), ya que W.F. Albright explicaba la palabra kinahhi como un adjetivo hurrita que significaba púrpura, por lo que Canaán sería un apelativo de Fenicia como el país del tinte de ese color. Como comentaba W. Röllig hace unas décadas citando precisamente a W.F. Albright $(1949,109)$, en la interpretación bíblica tradicional ...the Canaanites... after a long eclipse and a fresh transfusion of blood they were to emerge as a vital new people, the Phoenicians (Röllig, 1983; 80). No será ésta la única interpretación que fuese aceptada en general pues, algo más tarde, W. Culican entre otros, matizaría que los fenicios serían el resultado de una mezcla de tribus semitas recién llegadas con cananeos de la costa palestina (Culican, 1966, 72), es decir que, en el proceso, esas tribus semitas, sin que contasen con cualquier tipo de homogeneidad étnica o lingüística, fueron ocupando gradualmente los espacios dejados vacíos por la gente local conmocionada y alterada en la crisis del 1200 a.C. (Rollig, 1983, 93). Incluso se considera que fenicios y hebreos serían una misma gente, tal vez distinguiendo en principio simplemente y de forma general entre los fenicios como los comerciantes de la costa y los hebreos y otros los que vivían más al interior (Ganor, 2009, 270). Esa problemática llevará a J. Muhly, hace más de veinticinco años, a entender, como ahora, que la historia de los fenicios entre 1200 y 800 a.C. estaba todavía por hacer (Muhly, 1985, 187).

En el caso de S. Moscati $(1988,25)$, mucho más preciso y actual, los fenicios serían los navegantes que colonizaron Occidente, con una primera fase o pre-colonización similar a la egea experimentada en el Mediterráneo central y otra más tardía, ésta ya con intención colonizadora. En realidad S. Moscati (1983) paralelizaba la colonización fenicia con la de los griegos en el Mediterráneo Central, y la primera fase no implicaría la fundación de colonias o puestos permanentes, sino la frecuentación de mercados que no dejaba demasiada huella material, a pesar de que la permanencia comerciando en ellas podría ser muy amplia, hasta un año entero (Aubet, 2003, 99). Realmente, sin que faltase alguna prueba, estimaba que no hubo cualquier vacío comercial entre la empresa micénica y la fenicia propiamente dicha.
En este género de cosas, tampoco el modelo de conquista militar llevado a cabo por los primeros israelitas, según A.W. Albright (1941), que terminó con la Edad del Bronce en Canaán, puede mantenerse de acuerdo con el registro arqueológico actual, puesto que gran número de sitios nunca sufrieron cambios estructurales sino pequeñas rupturas, por lo que en caso que fuesen asimilados por unos recién llegados lo serían sin cualquier tipo de confrontación, sino más bien que, en general, se trató de un proceso de conformación de los futuros israelitas desde una gente que fueron simplemente cananeos de la Edad del Bronce (Dever, 1992, 101-104), bien sea que ya estuviesen en la árida zona montuosa o bien en la fértil costa.

\subsection{Navegantes Protofenicios:}

Por todo ello, para llegar a plantear diferencias históricas sustanciales en el tiempo y en el espacio mediterráneo, a la hora de nombrar a los marinos asentados en la costa con posterioridad a la crisis surge últimamente el ambiguo concepto de protofenicios, que no nos gusta demasiado, para distinguirlos de los nombrados fenicios por los griegos desde Homero (Aubet, 2003), de los que se cuenta con muy poca información escrita y datos arqueológicos objetivos que permitan ampliar nuestra noción sobre ellos (Stieglitz, 1990), excepto que fueron los comerciantes que hegemonizaron la zona en momentos previos al auge comercial, y tal vez político, de los habitantes de Tiro. También deberían integrarse en esta denominación a los navegantes con base en Chipre en el mismo período, que como se ha dicho fueron los continuadores del comercio del bronce que se había estancado durante la crisis generalizada del comercio micénico (Zaccagnini,1990) y los que, entre otras mercancías novedosas, inician la distribución del hierro a escala panmediterránea (Stampolidis, 2003, 42).

Estos navegantes chipriotas protofenicios necesitan también ser estudiados en profundidad, en especial para aclarar quiénes fueron, si únicamente nativos de la isla, simplemente chipriotas como en muchos casos se cuestiona o afirma con rotundidad, o bien descendientes de emigrantes micénicos del Egeo que coincidieron con otros inmigrantes orientales de la propia costa siropalestina que además deben sumarse al grupo (Voskos y Knapp, 2008), en realidad son otro conglomerado heterogéneo multiétnico. De hecho, la 
importancia de Chipre se mantendrá como referencia del comercio internacional al menos durante tres siglos para los navegantes del Egeo y, asimismo, para los de los puertos de la costa siropalestina (Karageorghis, 1982; 2005), pero nunca como un país sino como un conjunto de ciudadesestado independientes entre sí o puertos habitados por gentes de diversa procedencia, que en su ruta desde la costa siro-palestina hacia Egipto pasaban por la isla siguiendo las corrientes y los vientos favorables. Lo que tendrá gran importancia es la absorción y la hibridación con la población local por la continuada convivencia, tanto de gentes del Egeo como de la costa siro-palestina (Voskos y Knapp, 2008, 679).

De la misma forma y en esos momentos, en este efervescente mundo de contactos debemos contemplar también la presencia occidental en la isla mediterránea de objetos de bronce de génesis y procedencia atlántica, llevados desde la Península Ibérica, tales como el asador rotativo de bronce de Amathus (Karageorghis y Lo Schiavo, 1989), o las fíbulas tipo Huelva (Karageorghis, 1987, 719 y 723, fig. 193; Torres, 2008, 137; 2012), que también encuentran paralelos en Megiddo (Almagro Basch, 1957, 33) y en una tumba de Akziv (Mazar, 2004, fig. 28-1), aunque con ejemplares más tardíos que los que ahora se admiten en la Península Ibérica (Carrasco et al., 2006), donde en vez de importaciones como antes se entendían, deben ser tenidos como objetos de uso corriente pertenecientes a la sociedad local que comenzaba a orientalizarse.

En esta línea interpretativa de la historia del Próximo Oriente, los siglos XI-X a.C. son cruciales porque su geopolítica en general experimentó cambios sustanciales en lo que respecta a la supremacía de los intercambios comerciales ${ }^{9}$, y a todas luces la gradual incidencia de la presión asiria y la propia estructura del comercio oportunista de la Edad del Hierro, basado en productos con valor añadido y que fue la clave del período (Sherratt, 1998), darían lugar al ascenso como puerto hegemónico de la zona a Tiro pues, como resalta N. Chr. Stampolidis citando a M. Liverani, ...from the 11th c. B.C. onwards it is not Tyre that works for the international trade, but

9 Ello no implica que desde el II Milenio a.C. Tiro tuviese la necesidad y la capacidad para navegar por el Mediterráneo, sino que ese potencial se alcanzaría a partir de su consolida- rather it is the international trade that begins to work for Tyre (Liverani, 1991, 74; Stampolidis, 2003, 47). Por ello, teniendo en cuenta el texto bíblico, por la importancia que a través de la Biblia se ha dado a su rey Hiram I, los tirios -fenicios- se convertirán a partir de ese reinado en la referencia de los comerciantes de la Antigüedad, como todos han resaltado con asiduidad siguiendo claro está la interpretación deducida de textos redactados siglos más tarde, que los ha llevado hasta momentos demasiado antiguos y, por ello, ambiguos o poco concluyentes a nuestro juicio. Lo importante ahora, si históricamente desaparece el reino unificado, es establecer la importancia relativa para el conjunto siro-palestino del rey Hiram I de Tiro y su situación histórica.

Que Tiro fuese o no un puerto importante durante la Edad del Bronce, y cómo fuera su relación con los primeros conquistadores asirios, forma parte del debate actual (Stieglitz, 1990, 11; Aubet, 2009). Pero si entendemos que la hegemonía de Tiro se fue desarrollando gradualmente entre los siglos XI-X a.C., sería en un momento de esos siglos cuando comenzarán a documentarse en Chipre y también en Creta los hallazgos típicos procedentes de la pequeña isla situada a corta distancia de la costa (Bikai, 1987a, 70; 1987b; 2000), y por ello a resguardo de los ejércitos de enemigos continentales hasta la obra de Alejandro, aunque siempre podremos hablar de material tirio pero nunca asegurar que hubiese llegado en barcos fenicios de la ya expansiva Tiro, ni que necesariamente fuese una pista para explicar lo que tendría que documentarse en el Far West en relación con la presencia fenicia desde el siglo IX a.C. (Bikai, 2000, 311), solo para confirmar que el texto relativo a las naves de Tarsis (Reyes I, 10.22) se refiere a Occidente. Los materiales chipriotas del Horizonte Kouklia son conocidos en Tiro Estratos XIII-X, pero también están presentes en Tell Abu Hawam IV, Tell Keisan 9-7, Sarepta X-Y, y en las tumbas 4, 166 y 167 de Khaldé (Bikai, 1987a, Tabla2), que indica cuál sería su expansión en la costa siro-palestina y su distribución por ambas costas.

Entre los navegantes protofenicios del momento en cuestión debe recordarse todavía por

ción como centro hegemónico del comercio oportunista de la Edad del Hierro, en especial por su situación insular en la principal ruta de ese comercio. 
su profesión la presencia de Peleset, Tjekker y Shardana como antiguos pueblos del mar que permanecieron largo tiempo en algunos puertos de la costa (Negbi, 1992, 601), y serían precisamente sus puertos los conquistados por los fenicios de Tiro en su probable expansión militar hacia el sur, especialmente Dor, que en el texto de Unamón previamente estuvo gobernado por los Tjekker (Negbi, 1992, 603), por lo que los tirios aprovecharían la decadencia de esos pueblos del mar a partir del siglo XI a.C., o su circunstancial aumento de poder, para hacerse con ellos y convertirlos en sus bases (Negbi, 1992, 611), una circunstancia no aceptada por todos (Gilboa, 2013, 327-328). En los siglos XI-X a.C., incluso los navegantes procedentes de Tiro podrían ser considerados protofenicios, más que los líderes del futuro centro hegemónico de la zona.

\subsection{La expansión fenicia por el Mediterráneo. Cuándo y por qué:}

En realidad, dependiendo de su cronología siempre a debate (Negbi, 1992), todavía algún material, incluso durante gran parte del siglo $\mathrm{X}$ a.C., pudo distribuirse en naves protofenicias, tanto en barcos procedentes de la costa como en los viajes de retorno a Chipre o a Creta de sus navegantes locales que daban continuidad a la zona. Es el caso de los materiales orientales más antiguos de la selección de hallazgos descontextualizados recuperados en la bajamar de Huelva (González, Serrano y Llompart, 2004), según proponen A. Gilboa, I. Sharon y E. Boaretto (2009, 191), puesto que el grueso de las producciones tirias documentadas en el puerto atlántico son ya del siglo VIII a.C. (Gilboa, 2013), relacionadas claro está con ejemplos del $M G$ II griegos, lógicamente sincrónicos (Gómez, 2013). En cambio, los materiales centro-mediterráneos corresponden también a un momento algo más antiguo, que se ha relacionado con contactos previos de la sociedad del final de la Edad del Bronce del Suroeste con navegantes nurágicos (Fundoni, 2009; Gómez y Fundoni, 2011; Fundoni, 2013). También se han mostrado materiales locales de la transición del Horizonte Formativo al Clásico que hemos datado en torno al cambio de milenios (Gómez, 2008).

Desde la interpretación de los textos, se había estimado que la expansión fenicia por el Mediterráneo debería entenderse a partir de la pérdida del poder de los filisteos a manos del rey
David, no antes de la primera mitad del siglo $\mathrm{X}$ a.C., y el ascenso de los fenicios con su rey Hiram I (Gilboa, 2013, 316). La pasada década según E. Stern (1990), el puerto de Dor suministraba el necesario registro para indicar el cambio de hegemonía, con estratos de destrucción que dividía la fase previa de SKL/tjekker sea peoples a otra fase de dominación caracterizada por la coerción y expansión militar desde Fenicia (Gilboa, 2013, 316). Sin embargo, lo que no está claro es que esos pueblos del mar, filisteos u otros, dominasen el mar hasta la victoria de David y, por tanto, que a partir de esa victoria comenzara la expansión fenicia por el Mediterráneo (Gilboa, 2013, 324), que en realidad tendría que ser una consecuencia del nuevo poder alcanzado por los tirios.

Desde nuestro punto de vista, en ese largo proceso expansivo tirio, y tal vez de navegantes de otros puertos de la costa del actual Líbano, en momentos antiguos pudo influir el tradicional comercio de la madera tal como se observa en el texto de Unamón. Este comercio, que fue vital para la expansión de Tiro y además hay que considerarlo imprescindible para la construcción de sus famosos barcos y los de otras gentes, pudo haber sido puesto en peligro por las primeras acciones de la expansión militar asiria (Harden, 1967, 62). Según un texto fundacional donde Tiglath Pileser I presume de haber cortado madera de cedro para el templo de Anu y Adad en Asur, y que recibió tributo de Biblos, Sidón y de Arados (Bikai, 1992, 132), los tradicionales dueños de la madera debieron buscar una alternativa hacia el norte para aprovechar la de los bosques del Taurus, una posibilidad que sí está confirmada para los siglos IX-VIII a.C. (WatsonTreumann, 2001), pero que bien podría entenderse como una intención lógica de los primeros viajes hacia el norte, fuera del entorno costero tradicional (Lehmann, 2009, 162), más allá de Al Mina y de los puertos habituales en Chipre.

De cualquier forma, si nos preguntamos cuándo y por qué comenzó la expansión mediterránea de Tiro con otro interés que obtener madera, sino del comercio en general, dos episodios de los siglos X y IX a.C. serán fundamentales para justificar al menos con uno de ellos el por qué del inicio de las relaciones fenicias con Occidente, aunque ambos se deban a la interpretación de los textos, que implica que se produjo la necesidad de un cambio en la infraestructura del comercio tirio. 
En primer lugar, la expedición punitiva a Palestina del faraón Sheshonq I, quizá el Shishak bíblico (Fantalkin y Finkelstein, 2006; Finkelstein y Piasetzky, 2006; Chapman, 2009), causó la destrucción de algunos de los sitios mencionados en el texto sagrado y en la inscripción de Karnak (Ussishkin, 2007, 137), y por otra parte y entre otras consecuencias (Herrera y Gómez, 2004), pudo dar lugar a la imposibilidad de Tiro para continuar, por esa nueva muestra de poder egipcio que lo impediría militarmente, con su comercio ultramarino a través de el puerto de Elat, situado en el extremo norte del Mar Rojo, la Ezión-geber de Reyes I (9.26-28), que si se refiere a unas naves de Tarsis lo podría relacionar con otras vinculadas también con plata de otro texto de Reyes I (10.22), el tantas veces relacionado con Occidente.

Lo cierto es que a partir de Sheshonq-Shishak y desde el reinado de Josafat, se da por terminada la presencia fenicia y hebrea en la zona sur en favor de Egipto (Täckholm, 1969, 82-83), por lo que la consiguiente expansión mediterránea fenicia o tiria propiamente dicha estaría en función de la necesaria búsqueda de nuevos mercados donde obtener productos de calidad en un espacio no tratado específicamente por ellos anteriormente, aunque el Mediterráneo en general sí fuese ya conocido por otros navegantes desde siglos anteriores, especialmente navegantes procedentes de los puertos chipriotas y de los otros navegantes protofenicios que les antecedieron, sin que obviemos aquí que algunos marinos fenicios descendían de antiguos y poco concretos pueblos del mar y de protofenicios.

En segundo lugar, A. Fantalkin ha propuesto que la navegación por el Mediterráneo central y occidental sería consecuencia de la expansión y conquista aramea de gran parte del territorio por el rey Hazael de Damasco, aceptando también la propuesta de S. Frankenstein (1979) que se basó en que la incidencia de la presencia asiria convirtió a los tirios en sus agentes comerciales y de ahí su importancia en el siglo VIII a.C. (Fantalkin, 2006, 200), una posibilidad planteada también hace años por M.E. Aubet $(1986,16)$ que todavía podría seguir siendo válida si se ajusta su cronología (Aubet, 2008a, 182). De la forma que sea, bien a partir de Sheshonq I ( $c a .930)$, o bien desde Hazael de Damasco justo un siglo después ( $c a$. 830), las relaciones tirias con Occidente podrían inscribirse entre los años finales del siglo $\mathrm{X}$ y principios del siglo IX a.C., o bien a finales de este último, una horquilla temporal que precisamente coincide con una objetiva datación de los más antiguos materiales documentados últimamente en la zona intermareal de Huelva (Gómez y Fundoni, 2011).

Aunque se ha planteado que esa expansión colonial fue programada con tiempo y organizada por la élite comercial tiria, que sería la base de su comercio internacional (Aubet, 1987, 99), entendemos que también pudo haberse hecho desde su exclusiva vertiente comercial cuando todavía no parecía necesaria una emigración en masa por la amenaza asiria, lo cual no impediría la existencia de pequeños grupos asentados en los principales centros indígenas mediterráneos y atlánticos que, definitivamente, no pueden considerarse las típicas colonias fenicias como en el siglo pasado. Por lo tanto, los primeros asentamientos en el Mediterráneo en general deben entenderse como grupos de comerciantes situados, en el régimen que fuese (Alvar, 2008), en puertos de ultramar y nunca de colonos dominantes, como se piensa en el caso del Carambolo. Parece lógico que en los primeros momentos, por el número, modesto tamaño e infraestructuras (Aubet, 2006, 37-38), que solo la más cercana población local impondrá que las relaciones de los orientales pudieran basarse en una de las posibilidades contempladas por $\mathrm{J}$. Alvar, hegemónica o sometida al poder local.

Tal vez una de las excepciones sería Doña Blanca (Ruiz Mata, 1999), un asentamiento nuevo pensado para la explotación comercial del bajo Guadalquivir y la zona al interior del Guadalete y del Guadiamar, seguramente compartida por locales y fenicios desde su fundación, aunque estructuralmente fuese una ciudad oriental desde sus comienzos, y así continuaría siéndolo hasta el siglo III a.C. (Ruiz Mata y Pérez, 1995; Ruiz Mata y Gómez, 2008). El interés del modelo puede ser comparado y contrastado con el de Tavira, un sitio de la Edad del Bronce en Portugal (Maia y Gómez, 2012) que sería completamente orientalizado a partir de la segunda mitad del siglo VIII a.C. (Maia, 2003a-b; Maia y Fraga, 2004).

En tercer lugar, de acuerdo con todo lo anterior y como principal consecuencia, frente a las explicaciones tradicionales, hay que contemplar dos fases o ciclos sucesivos pero diferenciados en el tiempo y en sus objetivos para las relaciones producidas entre Oriente y Occidente: 
a) Una primera y prolongada fase, entre los siglos XIV y VIII a.C., estaría en función del comercio a larga distancia sin intención de fundar colonias permanentes innecesarias;

b) Otra más tardía, fundamental, que sí podría ponerse en relación con un proceso colonizador, o de búsqueda de ambientes donde asentarse lejos de la amenaza de los reyes asirios desde el último tercio del siglo VIII a.C.

En la primera fase se sucederán puntualmente navegantes orientales en general, y en la segunda ya únicamente los fenicios históricos capitalizados por Tiro, aunque también deberían incluirse a otros habitantes de la costa con sede en sus puertos. Desde esta perspectiva entendemos que no existió la paradigmática precolonización fenicia propiamente dicha como hace poco ha sido consensuado prácticamente por todos (Celestino, Rafel y Armada, 2008; Aubet, 2008b, 535; Gómez y Fundoni, 2011), sino que, lógicamente, bien las supuestas cronologías antiguas para la colonización fenicia de Occidente ya no pueden aceptarse a la ligera, al menos sin una explicación coherente con el registro histórico-arqueológico, pues hacer Historia no es un ejercicio de erudición o solo de interpretación textual razonada, o bien, como estamos proponiendo conceptualmente, que los elementos orientales previos a los siglos IX-VIII a.C. que recientemente se han ido localizando en Occidente, no pueden inscribirse simplemente al proceso colonizador, sino que llegaron para su intercambio en barcos de otros comerciantes orientales que, desde un punto de vista histórico, no pueden denominarse cándidamente colonos fenicios (Gómez y Fundoni, 2011; Gómez, 2013).

Entender a esos navegantes o comerciantes protofenicios como un momento o una fase previa donde esa denominación no los alejara de la principalidad histórica tiria de los fenicios de la costa siro-palestina, como ha propuesto M. E. Aubet al contemplar la fácil y cómoda posibilidad de subir los contactos previos a la tradicional expansión fenicia mediterránea (Aubet, 2008b, 535), a nuestro pesar entendemos que podría llevar a muchos, inconvenientemente al así cerrarse en falso el debate, a dudas de índole histórica.

\section{4.- COMO CONCLUSIÓN UNA PRO- PUESTA.}

A lo largo del desarrollo de la Protohistoria de la Península Ibérica, la sociedad occidental será influenciada por los contactos que, desde los últimos siglos del II Milenio a.C., tendrán lugar con navegantes orientales procedentes de diversos sitios del Próximo Oriente en general, aunque también con gentes del Mediterráneo Central, Cerdeña y tal vez Sicilia, ya fuesen locales autóctonos o solo inmigrantes procedentes del Egeo, de Chipre o de la costa siro-palestina allí asentados, o donde tenían sus bases.

Si los primeros contactos se han relacionado con navegaciones directas procedentes del Egeo, como podrían demostrar los hallazgos micénicos de Montoro, Carmona y otros sitios andaluces (Martín de la Cruz, 1987; 2008), los responsables de esos contactos previos no tuvieron por qué ser específicamente navegantes micénicos, pues otros barcos orientales durante los siglos XIV-XIII a.C. transportaron objetos micénicos, cretenses, chipro-micénicos, chipriotas, sirios, egipcios o de la costa siro-palestina, como demuestran los pecios de Uluburun (Pulak, 1998) o Cabo Gelidonia (Bass, 2010) entre otros, cargados con materiales de diversas procedencias. También, como se ha sugerido, esos objetos pudieron llegar a su destino a través de intermediarios centro-mediterráneos (Fundoni, 2013), una posibilidad que podría limitar la influencia directa de Oriente en esos primeros contactos, la cual no puede negarse a pesar de que el número de hallazgos todavía sea escaso para afinar cronologías.

La continuidad de las primeras relaciones entre Oriente y Occidente puede estar limitada por el contexto histórico general, toda vez que no podemos saber, pues no contamos con datos fehacientes de ello, cuál fue la incidencia efectiva de la crisis del 1200 a.C. en el desarrollo del proceso de cambio occidental, pues tal vez Occidente y el Mediterráneo central fuesen un escape o un refugio circunstancial para los que sufrían las convulsiones, como en el siglo VIII a.C. en relación con las conquistas asirias. Aunque lo lógico es que dado el colapso del mundo micénico preexistente se produjera un cambio estructural o tal vez la interrupción total durante décadas, a menos que fuesen navegantes centro-mediterráneos locales como los nurágicos, herederos de las técnicas y de los conocimientos náuticos micénicos, los que diesen con- 
tinuidad a unas relaciones que ya podían estar suficientemente consolidadas (Fundoni, 2013).

Durante los siglos XI-X a.C., de acuerdo con el registro arqueológico, se produjo un gran auge en las relaciones entre ambos espacios, de las cuales serían responsables los navegantes orientales que estamos denominando protofenicios, pues serían de un momento demasiado antiguo para relacionarlos directamente con los fenicios históricos. Como se ha visto más arriba, estos marinos nunca conformaron un grupo homogéneo que pueda asignarse a un estado, país o grupo étnico diferenciado, toda vez que su entidad o etnicidad estaría en función de la evolución del proceso histórico en esos siglos. Desde un punto de vista cronológico, en primer lugar, la mayoría cualitativa la deberían formar micénicos o chipro-micénicos asentados en los puertos chipriotas, además de otras gentes de procedencia también multiétnica de la costa siro-palestina, tales como descendientes de pueblos del mar, y cananeos o filisteos en general, y ya hemos visto que su génesis y evolución en esos siglos XI-X a.C. estuvo inducida por los factores que dieron lugar a su conformación como estados, o ciudades-estado, a lo largo de la Edad del Hierro.

Por lo tanto, aunque el comercio y las navegaciones pudieran estar interrelacionadas en la ruta natural del extremo oriental mediterráneo, cada uno de ellos pudo venir de cualquiera de los puertos localizados en esa ruta y, por lo tanto, serían personas diferenciadas entre sí, al menos desde un punto de vista político o estatal. De esa forma, por protofenicios no debemos entender a los representantes de un país o de una etnia, sino otro ...pretty cosmopolitan bunch (Sherratt, 1998, 307), como S. Sherratt denominó en su día a sus antecesores los pueblos del mar. Realmente fueron lo que W.F. Albright pensaba de los cananeos como comerciantes con un hubur, o grupo de ellos, o simplemente como lugar de comercio compartido por gentes de amplio signo y características regidos por leyes y/o convenios preestablecidos (Albright, 1975, 520).

De acuerdo también con los datos disponibles, en una segunda fase que todavía no puede estimarse cuál sería su extensión en el tiempo, los sitios chipriotas fueron perdiendo su hegemonía o preponderancia anterior, si es que alguna vez la ejercieron, en favor de al menos una de las ciudades estado de la costa libanesa. Tal vez por el avance asirio, los comerciantes de Tiro, cómodos en su isla situada en la ruta costera y a salvo por su flota de la presión directa de ese ejército continental, como se ha visto, fueron convirtiéndolo paulatinamente en una escala fácil con la infraestructura portuaria necesaria que fueron creando (Marriner, Morhange y Carayon, 2008), y cada vez más en un lugar seguro para la continuidad del comercio internacional, por más que se intente hacerlos progresar en cualquier problemática hegemonía política o militar que queramos otorgarles a partir de Hiram I y el texto bíblico.

Así, durante los siglos X-IX a.C., la isla y sus navegantes van a jugar el nuevo papel de protagonistas en el comercio internacional, que no quiere decir fuesen los únicos presentes en su desarrollo y, por problemas con los destinos previos y la incidencia de los faraones egipcios primero y de la política de los reyes asirios después, tendrán que abandonar la tradicional ruta comercial del Mar Rojo a través de Elat y se incorporarán plenamente al comercio con el norte de Siria. También, paulatinamente, intervendrán en el Mediterráneo en general, del cual se poseía suficiente conocimiento para no sentirse ajenos a su estructura específica, al menos del extremo más oriental, toda vez que tirios, sidonios y otros semejantes de los puertos de la costa descendían precisamente de los protofenicios anteriores, ya que la diferencia estructural con ellos solo debe ser cronológica y, fundamentalmente, de índole locacional, política o, mejor aún, histórica.

Ante las facilidades que se daban en esos momentos en el mundo del final de la Edad del Bronce en el conjunto de las costas europeas y africanas, el comercio de los siglos IX-VIII a.C. con las sociedades mediterráneas y atlánticas, va a posibilitar un cúmulo de oportunidades para la obtención de recursos tradicionalmente necesarios en general y perentorios a la hora de colmar la imposición de tributo por los reyes asirios, así como la posibilidad de traslados poblacionales a las, ahora ya sí, colonias, unos puertos donde asentar a la población que deberá huir ante la presión que supuso el cambio de estrategia que protagonizaría Tiglath Pileser III desde los inicios del último tercio de siglo VIII a.C.

A escala general del Mediterráneo oriental la imposición militar asiria significó un cambio drástico en la geopolítica de la zona por la ruptura del frágil equilibrio anterior, una modificación estructural de la que hay que entresacar, en favor de asirios, neo-babilonios y persas sucesivamente 
y con posterioridad, la preponderancia local previa de los estados secundarios creados en los dos siglos anteriores. Es ahora cuando debe entenderse la diáspora de Israel hacia Siria al norte por la deportación de gentes esclavizadas por los reyes asirios, pero también hacia la zona montañosa de Judá, un importante movimiento de población huída de sus tradicionales asentamientos del reino norte que convertiría a Jerusalén en una ciudad bien organizada en cuanto a población y con una relevancia regional que nunca tuvo, tal como será a fines del siglo VII a.C. durante el reinado de Josías.

Desde esta perspectiva histórica, delimitada en el tiempo entre los siglos finales del II Milenio y los primeros del I Milenio a.C., a juzgar por la procedencia de los diversos orientales que llevaron con ellos parte de su cultura material, además de su presencia comercial continuada durante esos siglos, incidieron en el desarrollo de una parte del Mediterráneo en general y de la Península Ibérica en particular, por lo que la sociedad occidental se incorporaría así, con pleno derecho, al mundo mediterráneo.

Desde estos nuevos planteamientos, que dejan sin sentido el arcaico paradigma de la Colonización Fenicia de Occidente y la ahora pretendida hegemonía de cananeos/fenicios en el Bajo Guadalquivir y en Huelva desde el siglo IX a.C., nuestra propuesta es abandonar para siempre la búsqueda de un registro arqueológico que confirme el paradigma anterior, como la ahistórica fundación de Gadir por los tirios en el II Milenio a.C. siguiendo el texto de Veleio Patérculo, o la sucesión de los tres viajes con escala en Almuñécar, en Saltés/Huelva y finalmente en Cádiz con el mismo propósito que, con todo respeto para los que piensen lo contrario, solo debe relacionarse con interpretaciones fundamentadas en textos redactados muchos siglos después del momento en que se habrían producido los hechos $\mathrm{y}$, por ello, dudosas y ambiguas por ser simples recreaciones de una realidad no confirmada desde la cientificidad.

De la misma forma, como la vinculación con Occidente del texto de la naves de Tarsis, especialmente relacionado ahora con Huelva, no puede sostenerse tanto con el lugar de procedencia de esas naves como con la cronología de un reinado salomónico que probablemente también es una recreación religiosa con otro sentido y no una descripción histórica real, su uso indiscrimi- nado, sin una explicación coherente con el registro arqueológico actual, debe considerarse un planteamiento de carácter científico obsoleto, superado por el análisis arqueológico actual, puesto que no es óbice que esas naves que llegaban a Israel también podrían proceder exclusivamente del Mar Rojo, incluso para los redactores del texto bíblico, o bien, que solo podrá aceptarse si algún día se localiza la arquitectura y la cultura material del reino unificado, hasta ahora inexistente.

Asimismo, adscribir a un mundo atemporal elementos orientales de todo tipo, tales como arquitecturas, elementos materiales de uso diario o cultuales de uso religioso, dioses y diosas, santuarios, altares, introducción de técnicas y nuevos productos como el hierro, la explotación de la plata, de la escritura oriental incluso la pre-alfabética, y tantas otras bondades que se han relacionado con los fenicios, solo debe quedar como algo superado en las revisiones de la investigación protohistórica que se hagan a partir de ahora. Como mínimo deben plantearse con una duda razonable.

Además, cuando se utilicen cronologías rediométricas para confirmar hechos que no pueden sostenerse desde un punto de vista bien anclado en la investigación de campo, nos debe llevar a la revisión del contexto arqueológico específico, teniendo en cuenta la procedencia de los elementos analizados, puesto que esa cronología, cualquiera que sea, solo podrá indicar la de los elementos orgánicos y no a todo el contexto, ya que éste puede ser de génesis postdeposicional o postocupacional amplia, y el fruto de sedimentaciones heterogéneas muy extensas en el tiempo.

La principal consecuencia para alcanzar un punto de partida, bien anclado en presupuestos históricos, que permita establecer hipótesis de trabajo coherentes con el resultado de la investigación más reciente, es que no se puede dejar para más adelante la revisión del paradigma de la Colonización Fenicia de Occidente y, en especial, sus bases explicativas. En este sentido, podemos resaltar aquí, tal como ha expuesto recientemente A. Gilboa, que durante los teóricos reinados de David y Salomón ...there is absolutely no evidence of any Phoenician 'move'-no Phoenicians conquering territories to the south of the Lebanon, no Phoenician colonies in Cyprus, no Phoenician "permanent post” at Kommos- nor anywhere else [...]. Y, más adelante, que ...The converging evidence [...] indicates [que] ...the 
first serious dispersal of Phoenicians to Mediterranean diasporas ...should be placed in the second half of the $9^{\text {th }}$ century BCE (Gilboa, 2013, 327-328).

Para el paradigma de la Colonización Fenicia de Occidente ya no existe consenso entre todos los investigadores que trabajan el tema y, por ello, debemos establecer nuevos modelos coherentes con el resultado de la investigación en el conjunto del Mediterráneo, en especial, desde nuestro punto de vista, a partir del registro arqueológico y su interpretación. Tal como se explicaba hasta ahora la colonización, desde una postura científica lógica, ya no se sustenta.

\section{BIBLIOGRAFÍA:}

ALBRIGHT, W.F. (1941): "New light on the early History of Phoenician colonization". BASOR, 83. Jerusalén.

-(1942): "The Role of the Canaanites in the History of Civilization". Studies in the History of Culture. Menasha, Wisconsin, 25, 50.

-(1943): "The Excavation of Tell Beit Mirsin III. The Iron Age". AASOR, 21-22.

-(1946): Archaeology and the Religion of Israel. The Johns Hopkins Press. Baltimore.

-(1949): The Archaeology of Palestine. Penguin, Harmondsworth, Middlesexh.

-(1975): "Syria, the Philistines and Phoenicia". En I.E.S. Edwards, N.G.L. Hammond y E. Sollberger (Eds.) History of the Middle East and the Aegean Region c. 1380-1000 B.C. The Cambridge Ancient History, Vol. II, Part 2. Cambrige University Press. 507-536.

ALMAGRO BASCH, M. (1957): "Las fíbulas de codo de la Ría de Huelva. Su origen y cronología". Cuadernos de Trabajos de la Escuela Española en Roma 9, 7-46.

ALMAGRO GORBEA, M. (1977): El Bronce Final y el Período Orientalizante en Extremadura. Bibliotheca Praehistorica Hispana XIV. Madrid.

-(1993): "La introducción del hierro en la Península Ibérica. Contactos precoloniales en el Período Protoorientalizante". Complutum, 4. 81-94
-(2013): "La sociedad tartésica". En J.M. Campos y J. Alvar (Eds.) Tarteso. El Emporio del Metal. Almuzara, Córdoba, 491-509.

ALVAR, J. (2008): "Modos de contacto y medios de comunicación: los orígenes de la expansión fenicia”. En S. Celestino, N. Rafel, y X.L. Armada (Eds.) Contacto cultural entre el Mediterráneo y el Atlántico (siglos XIIVIII ane). La pre-colonización a debate. Serie Arqueológica - II. Escuela Española de Historia. Madrid, 19-25.

AMIRAN, R. (1969): Ancient Pottery of the Holy Land: From Its Beginnings in the Neolithic Period to the End of the Iron Age. The Biyalik Institute y The Israel Exploration Society. Massada Press, Jerusalén. (en especial sus capítulos sobre la Edad del Hierro).

ANDERSON, W.P. (1981): A Stratigraphic and Ceramic Analysis of the Late Bronze and Iron Age Strata of Sounding $Y$ at arepta, Sarafand. Lebanon. University Microfilm Int. Ann Arbor, Michigan.

ARTEAGA, O. (1995): "Paradigmas historicistas de la civilización occidental. Los fenicios en las costas mediterráneas de Andalucía”. Spal, 4. 131-171.

ASTOUR, M.C. (1965): "The Origin of the terms 'Canaan', 'Phoenician', and 'Purple'". Journal of Near Eastern Studies, 24, 4. 346350 .

AUBET SEMMLER, M.E. (1986): "Los fenicios en España. Estado de la cuestión y perspectivas". Aula Orientalis 3. Barcelona, 9-38.

-(1987): Tiro y las colonias fenicias en Occidente. Bellaterra, Barcelona.

-(2003): "El comercio fenicio en Homero". En S.M. Ramallo (Ed.) Estudios de Arqueología dedicados a la profesora Ana María Muñoz Amilibia. Universidad de Murcia, 85-101.

-(2006): "El sistema colonial fenicio y sus pautas de organización”. Mainake, XXVIII. 35-47.

-(2008a): "Political and economic implications of the new Phoenician chronologies". En C. Sagona (Ed.) Beyond the Homeland: Markers in Phoenician Chronology. Ancient Near Eastern Studies, Suppl. 28. Lovaina, 247-259. 
-(2008b): "Epílogo: La Pre-Colonización vista desde Oriente". En S. Celestino y J. Jiménez (eds.) El período orientalizante. Actas del III Simposio Internacional de Arqueología de Mérida: Protohistoria del Mediterráneo Occidental. Anejos de Archivo Español de Arqueología 35. Madrid, 535.

-(2009): "Byblos y Tiro. Desarrollo y reestructuración urbanísticas en Fenicia". S. Helas y D. Marzoli (Eds.), Phönizisches und punisches Städtwesen, Iberia Archaeologica 13, Mainz, 21-37.

BALENSI, J. (1980): Les Fouilles de R.W. Hamilton à Tell Abu Hawam, Niveau IV e V : dossier sur l'histoire d'un port Mediterraneén durant les âges du Bronze et du fer (i 1600-950 av. J.C.). Tesis doctoral, Université des Sciences Humaines, Estrasburgo.

-(1985): "Revising Tell Abu Hawam". BASOR, 257. 65-74.

-(1988): "Tell Abu Hawam: Un cas exceptionnel?". En M. Heltzer y E. Lipinski (Ed.) Society and Economy in the Eastern Mediterranean (c. 1500-1000 B.C. ). Lovania, 305-311.

-(2004): "Relativité du phénomène mycénien à Tell Abou Hawam : un $<<$ ProtoMarketing $>>$ ?. En J. Balensi, J.Y. Monchambert y S. Müller Celka (Eds.) La céramique mycénienne de l'Égée au Levant. Hommage à Vronwy Hankey. Travaux de la Maison de l'Orient et de la Méditerrnée, 41. Lyon, 141-181.

BALENSI, J., HERRERA, M.D. y ARTZY, M. (1993): “Abu Hawam, Tell”. En E. Stern, A Gilboa-Lewingson (Eds.) The New Encyclopedia of Archaeological Excavations en the Holly Land. Israel Exploration Society y Carta, Vol. 1. Jerusalén, 7-14.

BARAMKI, D. (1961): Phoenicia and the Phoenicians. Beirut.

BASS, G.F. (2010): "Cape Gelidonya shipwreck". En E.H. Cline (Ed.) The Oxford Handbook of the Bronze Age Aegean (ca. 3000-1000 BC). Oxford University Press, 797-803.
BELMONTE, J.A. (2007): "Fenicia. De las ciudades-estado independientes a la lucha por la autonomía". En J.L. López Castro (Ed.) Las ciudades fenicio-púnicas en el Mediterráneo Occidental. Centro de Estudios Fenicios y Púnicos y Editorial Universidad de Almería. 19-42.

BENDALA GALÁN, M. (1992): "El mundo feniciopúnico y su expansión mediterránea". En La Prehistoria de les Illes de la Mediterrània Occidental. X Jornades d'Estudis Històrics Locals. Palma de Mallorca, 375-391.

-(2013): "La génesis de Tarteso en la etapa "precolonial' del segundo milenio: Notas para una discusión". En J.M. Campos y J. Alvar (Eds.) Tarteso. El Emporio del Metal. Almuzara, Córdoba, 123-135.

BERNARDINI, P. (2006): "Phoinikes e Fenici lungo le rotte Mediterranee". En A. Mastino, P.G. Spanu y R. Zucca (Ed.) Tharros Felix 2. Roma, 197-242.

BIKAI, P.M. (1978): The Pottery of Tyre. Warminster.

-(1987a): The Phoenician Pottery of Cyprus. Nicosia.

-(1987b): "The Phoenician Pottery". En V. Karageorghis, O. Picard y Chr. Tygat (Ed.) La Nécropole d'Amathonte Tombes 113-367. II. Céramiques non Chypriotes. Etudes Chypriotes VIII. Nicosia, 1-19.

-(1992): "The Phoenicians". En W.A. Ward y M.S. Joukowsky (Eds.) The Crisis Years: The 12th Century B.C. From Beyond the Danube to the Tigris. Dubuque IA, 132-141.

-(2000): "Phoenician Ceramics from the Greek Sanctuary". En J.W. Shaw y M.C. Shaw (Ed.) Kommos IV. The Greek Sanctuary, Part 1. Princeton, 302-312.

BLÁZQUEZ, J.M. (1968): Tartessos y los orígenes de la colonización fenicia en Occidente. Universidad de Salamanca.

-(2002): "La precolonización y la colonización fenicia. El período orientalizante en la Península Ibérica. Estado de la cuestión". AEspA, 75. 37-57.

-(2005): "Evolución del concepto orientalizante en los últimos 50 años en la investigación hispana". En S. Celestino y J. Jiménez (eds.) El período orientalizante. Actas del III 
Simposio Internacional de Arqueología de Mérida: Protohistoria del Mediterráneo Occidental. Anejos de Archivo Español de Arqueología 35. Madrid, 129-148.

BODINE, J.J. (2010): Gates, Dates, and Debates: A Review of Megiddo's Monumental Gate and the Debates over Archaeology and Chronology in Iron Age Palestine". Studia Antiqua 8. Provo, Utah, 5-23.

BRIEND, J. y HUMBERT, J.B. (1980): Tell Keisan. 1971-1976. Une cite phenicienne en Galilee. Freibourg-Gottingen.

BRUINS, H.J, NIJBOER, A.J. y PLICHT, J. van der (2011): "Iron Age Mediterranean Chronology: A Reply". Radiocarbon, Vol 53, Nr 1. 199-220.

CAHILL, J.M. (2003): "Jerusalem at the Time of the United Monarchy: The Archaeological Evidence". En A.G. Vaughn y A.E. Killebrew (Eds.) Jerusalem in Bible and Archaeology: The First Temple Period. Society of Biblical Literature. 13-80.

CARPENTER, R. (1958): "Phoenicians in the West". American Journal of Archaeology, 62 (1). 35-53

CARRASCO RUS, J.A.; PACHÓN, J.A., ESQUIVEL, J.A. y ARANDA, G. (2006): "Sobre la cronología de las Fíbulas de Codo tipo Huelva". Archivo de Prehistoria Levantina, Vol. XXVI. Valencia, 245-291.

CELESTINO, S., RAFEL, N. y ARMADA, X.L., Eds. (2008) Contacto cultural entre el Mediterráneo y el Atlántico (siglos XII-VIII ane). La precolonización a debate. Serie Arqueológica - II. Escuela Española de Historia y Arqueología de Roma. CSIC. Madrid.

CHAPMAN, R.L. (2009): "Putting Sheshonq I in his Place”. Palestine Exploration Quarterly, $141,1,4-17$.

CHAPMAN, S.V. (1972): “A catalogue of Iron Age pottery from the cemeteries of Khirbet Silm, Joya, Qrayé and Qasmieh of South Lebanon with a note on the Iron Age Pottery of the American University Museum, Beirut". Berytus 21. 55-194.

CUADRADO DÍAZ, E. (1953): "Materiales ibéricos: Cerámica roja de procedencia incierta”. Zephyrus, IV. Salamanca.
-(1969): "Origen y desarrollo de la cerámica de Barniz Rojo en el mundo Tartésico". En J. Maluquer (Ed.) Tartessos y sus problemas. V Symposium internacional de Prehistoria Peninsular. Jerez de la Frontera, Septiembre 1968. Universidad de Barcelona. 257-290.

CULICAN, W. (1966): The First Merchant Venturers: The Ancient Levant in History and Commerce. Thames \& Hudson, Londres.

-(1982): "The Repertoire of Phoenician Pottery". En H.G. Niemayer (Ed.) Phonizier im Westen. Madrider Beiträge, 8. Maguncia, 4582.

DEL OLMO, G. y AUBET, M.E., Edrs. (1986): Los fenicios en la Península Ibérica. Aula Orientalis, III-IV. Sabadel.

DEVER, W.G. (1992): "The Late Bronze-Early Iron I Horizon in Syria-Palestine: Egypcians, Canaanites, 'Sea Peoples', and ProtoIsraelites". En W.A. Ward y M.S. Joukowsky (Eds.) The Crisis Years: The 12th Century B.C. From Beyond the Danube to the Tigris. Dubuque IA, 99-110.

DONGEN, E. von (2010): 'Phoenicia': Naming and Defining a Region in Syria-Palestine". En R. Rollinger, B. Gufler, M. Lang e I. Madreiter (Eds.) Interkulturalität in der Alten Welt Vorderasien, Hellas, Ägypten und die vielfältigen Ebenen des Kontakts. Harrassowitz Verlag. Wiesbaden, 471-488.

DOTHAN, T. (1992): "Social Dislocation and Cultural Change in the $12^{\text {th }}$ Century BC.E.". En W.A. Ward y M.S. Joukowsky (Eds.) The Crisis Years: The 12th Century B.C. From Beyond the Danube to the Tigris. Dubuque IA, 93-98.

EGBERT, A. (1991): "The Chronology of 'The Report of Wenamun"”. The Journal of Egyptian Archaeology, 77. 57-67.

ESCACENA CARRASCO, J.L. (2013): "El espejismo tartésico". En J.M. Campos y J. Alvar (Eds.) Tarteso. El Emporio del Metal. Almuzara, Córdoba, 137-195.

FANTALKIN, A. (2006): "Identity in the Making: Greeks in the Eastern Mediterranean during the Iron Age" En A. Villing y U. Schlotzhauer (Ed.) Naukratis: Greek Diversity in Egypt. Studies on East 
Greek Pottery and Exchange in the Eastern Mediterranean. The British Museum Research Publication 162. Londres, 199-208.

FANTALKIN, A. y FINKELSTEIN, I. (2006): "The Sheshonq I Campaign and the $8^{\text {th }}$. Century-BCE Earthquake- More on the Archaeology and History of the South in the Iron I-IIA". Tel Aviv 33. 18-42.

FAUST, A. (2000): "Ethnic complexity in Northern Israel during Iron Age II". Palestine Exploration Quaterly, 132. 2-27.

-(2010): "The Large Stone Structure in the City of David. A Reexamination”. Zeitschrift des Deutschen Palästina-Vereins, 126, 2. 116-130.

FEINMAN, P.D. (2004). William Foxwell Albright and the Origins of Biblical Archaeology. Andrews University Press. Berrien Springs.

FERNÁNDEZ, A. y RODRÍGUEZ, A. (2010): "El Carambolo, secuencia cronocultural del yacimiento. Síntesis de las intervenciones 2002- 2005". En $\mathrm{M}^{\mathrm{a}}$.L. de la Bandera y E. Ferrer (Coords.) El Carambolo, 50 años de un tesoro. Sevilla, 203-270.

FINKELSTEIN, I. (1996): "The Archaeology of the United Monarchy: an Alternative View". Levant XXVIII, 177-187.

-(2001): "The Rise of Jerusalem and Judah: the Missing Link". Levant 33, 105-115.

-(2006): "The Iron I-IIA in the Highlands and Beyond: 14C Anchors, Pottery Phases and The Shoshenq I Campaingn". Levant 38. 45-61.

-(2008): "The Settlement History of Jerusalem in the eighth and seventh Centuries BC". R.B., 115-4. 499-515.

-(2011a): "The 'Large Stone Structure' in Jerusalem. Reality versus Yearning". Zeitschrift des Deutschen Palästina-Vereins 127. 1-10.

-(2011b): "Stages in the Territorial Expansion of the Northern Kingdom". Vetus Testamentum 61. 227-242.

-(2012): “The Great Wall of Tell en-Nasbeh (Mizpah), The First Fortifications in Judah, and 1 Kings 15:16-22". Vetus Testamentum 62. 14-28.

FINKELSTEIN, I. y PIASETZKY, E. (2006): "The Iron I-IIA in the Highlands and Beyond:
14C Anchors, Pottery Phases and The Shoshenq I Campaign". Levant 38. 45-61.

FINKELSTEIN, I., KOCH, I. y LIPSCHITS, O. (2011): "The Mound on the Mount: A Possible Solution to the 'Problem with Jerusalem"'. The Journal of Hebrew Scriptures, 11. 2-24.

FINKELSTEIN, I, HERZOG, Z., SINGERAVITZ, L., USSISHKIN, D. (2007): "Has King David's Palace in Jerusalem Been Found?". Tel Aviv 34, 142-164.

FLEMING, W.B. (1915): The History of Tyre. Columbia University Oriental Studies, X. Lancaster - New York.

FRANKENSTEIN, S. (1979): "The Phoenicians in the Far West: A Function of Neo-Assyrian Imperialism". En M.T. Larsen (Ed.) Power and Propaganda: A Symposium on Ancient Empires. Copenhagen Studies in Assyriology 7. Copenague, 263-294.

FUNDONI, G. (2009): "Le relazioni tra la Sardegna e la Peninsola Iberica nei primi secoli del I Millennio a.C.: le testimonianze nuragiche nella Peninsola Iberica". Anales de Arqueología Cordobesa 20. 11-34.

-(2013): La relazioni tra la Sardegna e la Peninsola Iberica tra il Bronzo Finale e la prima età del Ferro attraverso le testimonianze archerlogiche (secoli XII-VII a.C.). Tesis Doctoral, inédita. Universidad de Córdoba.

GALÁN, J.M. (2000): Cuatro Viajes en la Literatura del Antiguo Egipto. Consejo Superior de Investigaciones Científicas. Madrid.

GANOR, N.R. (2009): Who were the Phoenicians? Kotarinm International Publishing Ltd. Eisenbrauns. Winona Lake.

GARCIA SANJUAN, L. y HURTADO, V. (2011): "Las dataciones radiocarbónicas de El Trastejón en el marco de la cronología absoluta de la Edad del Bronce (c. 2200-850 cal. ANE) en el Sur de la Península Ibérica". En V. Hurtado, L. García Sanjuán y M. Hunt (eds.): El Asentamiento de El Trastejón (Huelva). Investigaciones en el Marco de los Procesos Sociales y Culturales de la Edad del Bronce en el Suroeste de la Península Ibérica. Sevilla, 138-161. 
GARCÍA SANJUÁN, L. y ODRIOZOLA LLORET, C. (2012): "La cronología radiocarbónica de la Edad del Bronce (c. 2200-850 cal ANE) en el Suroeste de la Península Ibérica”. En J. Jiménez Ávila (Ed.) Sidereum Ana II. El río Guadiana en el Bronce Final. Anejos de AEspA LXII. Mérida (Badajoz), 363-387.

GILBOA, A. (2005): "Sea Peoples and Phoenicians along the Southern Phoenician Coast - A Reconciliation: An Interpretation of Sikila (SKL) Material Culture". BASOR, 337. 47-78.

-(2007): "Fragmenting the Sea Peoples, with an Emphasis on Cyprus, Syria and Egypt: A Tel Dor Perspective. The Philistine Paradigm". Scripta Mediterranea, XXVII-XXVIII. 209-244.

GILBOA, A., SHARON, I. y BOARETTO, E. (2009): "Tel Dor and the chronology of Phoenician "pre-colonization" stages. In C. Sagona (Ed.) Beyond the Homeland: Markers in Phoenician Chronology. Monograph Series of Ancient Near Eastern Studies. Lovaina, 113-204.

GITIN, S., MAZAR, A. y STERN, E., Eds. (1998): Mediterranean Peoples in transition. Thirteenth to Early Tenth Century BCE. Jerusalén.

GJERSTAD, E. (1948): The Cypro-Geometric, Cypro-Archaic and Cypro-Classical Periods. Finds and results of the excavations in Cyprus, 1927-1931. The Swedish Cyprus Expedition, IV: 2, Stockholm.

-(1960): "Pottery from various parts of Cyprus". En E. Gjerstad (Ed.) Greek Geometric and Archaic Pottery found in Cyprus. Act. Inst. Regni Sueciae, XXVI. Lund.

GOMÉZ TOSCANO, F. (1998): El final de la Edad del Bronce entre el Guadiana y el Guadalquivir. Servicio de Publicaciones de la Universidad de Huelva. Sevilla.

-(2006): "El final de la Edad del Bronce entre el Guadiana y el Guadalquivir. Síntesis histórico-arqueológica según las más recientes evidencias". Madrider Mitteilungen, 47. 24-42.

-(2008): “Cerámicas del Bronce Final en Huelva (1200-600 a.C.). Nueva tipología para explicar su amplitud cronológica". Homenaje a
Pilar Acosta. Tabona, 16. Universidad de la Laguna (Tenerife), 85-100.

-(2013a): “Contactos con el Mediterráneo Oriental en el Suroeste de la Península Ibérica durante los siglos XIV-VIII a.C. ¿Marinos orientales o fenicios atemporales? Revista Onoba, $\mathrm{N}^{\mathrm{o}}$ 1. Universidad de Huelva. 79-98.

-(2013b): "El Mundo Mediterráneo y Tarteso a la luz de nuevas evidencias". En J.M. Campos y J. Alvar (Eds.) Tarteso. El Emporio del Metal. Almuzara, Córdoba, 289-309.

GÓMEZ TOSCANO, F. y BALENSI, J. (1999): "La colección de vasos egeos de Tell Abu Hawam (Haifa, Israel) y su relación con la cronología histórica de la expansión fenicia en occidente". Huelva en su Historia, 2. 4370.

GÓMEZ TOSCANO, F. y FUNDONI, G. (2011): "Relaciones del Suroeste con el Mediterráneo en el Bronce Final (siglos XI-X a.C.), Huelva y la isla de Cerdeña. Anales de Arqueología Cordobesa, 21. Córdoba, 11-34.

GONZÁLEZ CANALES, F., SERRANO AGUILAR, L. y LLOMPART, J. (2004): $E l$ Emporio Fenicio Precolonial de Huelva, ca. 900-770 a.C. Biblioteca Nueva. Madrid.

GÜTERBOCK, H.G. (1992): "Survival of the Hittite Dynasty". En W.A. Ward y M.S. Joukowsky (Eds.) The Crisis Years: The 12th Century B.C. From Beyond the Danube to the Tigris. Dubuque IA, 53-55.

HADJISAVVAS, S. (2007): "Who were the Residents of the Ashlar Buildings in Cyprus". En S. Müller y J.C. David (Ed.) Patrimoines culturels en Méditerranée orientale : recherche scientifique et enjeux identitaires. Chypre, une stratigraphie de l'identité. Lyon, 1-7.

HALLOTE, R. (2011): "Before Albright. Charles Torrey, James Montgomery, and American Biblical Archaeology, 1907-1922". Near Eastern Archaeology, 74. 3. 156-169.

HAMILTON, R.W. (1935): "Excavations at Tell Abu Hawam". Quaterly of the Department of Antiquities of Palestine, 4. 1-69.

HARDEN, D. (1967): Los Fenicios. Ayma. Barcelona. 
HERRERA, M.D. y BALENSI, J. (1986): "More about the Aegean Geometric Imports from Tell Abu Hawam”. Levant 18. 169-171.

HERRERA, M.D. y GÓMEZ, F. (2004): Tell Abu Hawam (Haifa, Israel). El horizonte fenicio del Stratum III británico. Huelva.

HERZOG, Z. y SINGER-AVITZ, L. (2004): "Redefining the Centre: The emergence of State in Judah". Tel Aviv 31. 209-244.

HUMBERT. J.B. (1981): "Recent travaux a Tell Keisan (1979-1980)". Revue Biblique, 88. Jerusalén, 373-398.

JAMES, P., KOKKINOS, N. y THORPE, I.J. (1998): "Mediterranean Chronology in Crisis". En M.S. Balmuth y R.H. Tykot (Eds.) Sardinian and Aegean Chronology: Towards the Resolution of Relative and Absolute Dating in the Mediterranean. Studies en Sardinian Archaeology V Oxbow Books. Oxford, 29-43.

JEFFREY, P.E. (2013): “'Srdn from the Sea': The Arrival, Integration, and Acculturation of a 'Sea People'“. Journal of Ancient Egyptian Interconnections, Vol. 5: 1. 14-27.

JIMÉNEZ ÁVILA, J. y GUERRA MILLÁN, (2012): El Bronce Final en Medellín: Estudio preliminar del Corte 'Smro'". En J. Jiménez Ávila (Ed.) Sidereum Ana, II. El río Guadiana en el Bronce Final. Anejos de AespA, LXII. Mérida (Badajoz), 65-110.

JOFFE, A.H. (2002): "The rise of Secondary States in the Iron Age Levant". JESHO 45, 4. Koninklijke Brill NV, Leiden, 425-467.

KAHN, D. (2011): "The Campaign of Ramesses III against Philistia". Journal of Ancient Egyptian Interconnectios, Vol. 3: 4. 1-11.

KARAGEORGHIS, V. (1982): "Cyprus between the Orient and the Occident in the eleventh century B.C.". Archéologie au Levant. Recueil R. Saidah. CMO 12. Sér. Arch. 9. Lyon, 173-178.

-(1987): "Chronique des fouilles et découvertes archéologiques à Chypre en 1986, BCH 101, 663-733.

-(2002): Early Cyprus. Crossroads of the Mediterranean. P. Getty Museum, Los Ángeles.

-(2005): “The Phoenicians in Cyprus". En S. Celestino y J. Jiménez (Eds.) El Período
Orientalizante. Anejos de AEspA XXXV, Vol. I. 31-46.

KARAGEORGHIS, V. y LO SCHIAVO, F. (1989): "A west Mediterranean obelos from Amathus". Rivista di Studi Fenici 17 (1): 1529.

KATZENSTEIN, H.J. (1973): The history of Tyre. From the beginning of the second millennium B.C.E. until the fall of the Neo-Babylonian empire in 538 B.C.E. Jerusalén.

KENYON, K.M. (1964): "Megiddo, Hazor, Samaria and Chronology". Bulletin of the Institute of Archaeology, 4. 143-152.

KNAPP, A.B. (2009): "Migration, Hybridisation and Collapse: Bronze Age Cyprus and the Eastern Mediterranean". En A. Cardarelli et. al. (Eds), Scienze dell'antichità, Storia Archeologia Antropologia, 15. Università Degli Studi di Roma <<La Sapienza $>>$. Roma, 219-239.

LEHMANN, G. (2009): "North Syria and Cilicia, c. 1200-330 BCE". En C. Sagona (Ed.) Beyond the Homeland: Markers in Phoenician Chronology. Ancient Near Eastern Studies, Suppl. 28. Lovaina, 137178.

LERIOU, A. (2011): "Overseas migrations at the end of the Late Bronze Age in the Aegean and the eastern Mediterranean: some reflections". En G. Vavouranakis (Ed.) The Seascape in Aegean Prehistory. Monographs of the Danish Institute at Athens, 14. 251270 .

LIVERANI, M. (1991): “The Trade Network according to Ezeq, 27". Studies in Assyrian History and Ancient Near Eastern Historiography presented to H. Tadmor, Scripta Hierosolymitana, XXXIII. 65-79.

LÓPEZ CASTRO, F. (1992): "La colonización fenicia en la Península Ibérica: 100 años de investigación". La colonización fenicia en la Península Ibérica: 100 años de investigación. Granada, 11-79.

LÓPEZ PARDO, F. (2004): Crono y Briareo en el umbral del Océano. Un recorrido por la historia mítica de los viajes al confín del Occidente hasta los albores de la colonización. En V. Peña, A. Mederos y C.G. Wagner (Eds.) La navegación fenicia. Tecnología naval y derroteros. Madrid, 1-42. 
LUCAS PELLICER, R. (1998): “Algo más sobre el Tesoro de Villena: Reconstrucción parcial de tres empuñaduras". CuPAUAM, 25.1, 157199.

MAIA, M. (2003a): “O Bronze Final Pré-fenicio no Concelho de Tavira". En Tavira, Territorio e Poder. Museo Nacional de Arqueología y Cámara Municipal de Tavira. Lisboa, 39-47.

-(2003b): "Fenicios en Tavira". En Tavira, Territorio e Poder. Museo Nacional de Arqueología y Cámara Municipal de Tavira. Lisboa, 57-72.

MAIA, M. y FRAGA, L. (2004): "O culto de Baal em Tavira". Actas de III Congreso Español del Antiguo Oriente Próximo. Huelva Arqueológica, 20. Huelva, 171-194.

MAIA, M. y GÓMEZ, F. (2012): "Um achado da idade do bronze em Tavira". En J. Jiménez Ávila (Ed.) Sidereum Ana, II. El río Guadiana en el Bronce Final. Anejos de AespA, LXII. Mérida (Badajoz), 327-344.

MAISLER (Mazar), B. (1946): "Canaan and the Canaanites". BASOR, 102. 7-12.

MALUQUER DE MOTES, J., Ed. (1969): Tartessos y sus problemas. V Symposium internacional de Prehistoria Peninsular. Jerez de la Frontera, Septiembre 1968. Universidad de Barcelona.

MALUQUER DE MOTES, J. (1970): Tartessos. Ediciones Destino. Barcelona.

MARRINER, N., MORHANGEM C. y CARAYON, N. (2008): "Ancient Tyre and its harbours: 5000 years of human-environment interactions". Journal of Archaeological Science, 35. 1281-1310.

MARTÍN DE LA CRUZ, J. C. (1987): "Cerámicas micénicas en Andalucía". Revista de Arqueología, 78. 62-64.

-(1988): "Mykenische Keramik aus Bronzezeitlichen Siedlungschichten von Montoro am Guadalquivir". Madrider Mitteilungen, 29. 77-92.

MARTÍN RUIZ, J.A. (1995): Catálogo Documental de los Fenicios en Andalucía. Junta de Andalucía. Sevilla.

MAZAR, A. (2005): "The Debate over the Chronology of the Iron Age in the Southern Levant. Its history, the current situation, and a suggested resolution". En T.E. Levy y T. Higham (Ed.) The Bible and Radiocarbon Dating: Archaeology, Text and Science. Londres, 15-30.

-(2006): "Jerusalem in the 10th Century BCE. The Glass Half Full". En Y. Amit et al. (Eds.) Essays on Ancient Israel in Its Near Eastern Context. A Tribute to Nadav Na aman (Winona Lake). 255-272.

-(2010): "Archaeology and the Biblical Narrative: The Case of the United Monarchy". En R. G. Kratz y H. Spiekermann (Ed.) One GodOne Cult-One Nation: Archaeological and Biblical Perspectives. Beihefte zur Zeitschrift für die alttestamentliche Wissenschaft, 405. Berlín, 29-58.

-(2011): "The Iron Age chronology debate: is the gap narrowing? Another viewpoint". Near Eastern Archaeology 74. 105-110.

MAZAR, E. (2004): The Phoenicians Family Tomb N.1 at the Northern Cemetery of Achziv (10 th-6th Centuries BCE). Cuadernos de Arquelogía Mediterránea, 10. Barcelona.

-(2009): "The Palace of King David. Excavations at the Summit of the City of David". Preliminary Report of Seasons 2005 - 2007. Jerusalén.

MEDEROS MARTÍN, A. (2001): "Fenicios evanescentes. Nacimiento, muerte y redescubrimiento de los fenicios en la Península Ibérica. I. (1780-1935)". Sagvntvm (P.L.A.V.), 33. 37-48.

-(2004): "Fenicios evanescentes. Nacimiento, muerte y redescubrimiento de los fenicios en la península Ibérica. II. (1936-1968)". Sagvntvm (P.L.A.V.), 36. 35-46.

MONGE SOARES, A. (2005): "Os povoados do Bronze Final do Sudoeste na margem esquerda portuguesa do Guadiana: novos dados sobre a cerâmica de ornatos brunidos". Revista Portuguesa de Arqueologia 8 (1), 111-145.

MOSCATI, S. (1983): "Precolonizazazione greca e precolonizzazione fenicia". Rivista di Studi Fenici, XI, 2. 4-18.

-(1988): "Chi furono I Fenici”. En S. Moscati (Dr.) I Fenici. Bompiani. Milán, 24-25.

MUHLY, J. (1985): "Phoenicia and the Phoenicians". International Congress on Biblical Archaeology Today. Jerusalén, 177191. 
-(1992): "The Crisis Years in the Mediterranean World: Transition or Cultural Disintegration?". En W.A. Ward y M.S. Joukowsky (Eds.) The Crisis Years: The 12th Century B.C. Dubuque IA, 10-26.

NA'AMAN, N. (1986): "Habiru and Hebrews: The Transfer of a Social Term to the Literary Sphere". Journal of Near Easter Studies, vol. 45, no. 4. 271-288.

-(1996): "The Contribution of the Amarna Letters to the Debate on Jerusalem's Political Position in the Tenth Century B.C.E.". BASOR, 304. 18-27.

NEGBI, O. (1992): "Early Phoenician Presence in the Mediterranean Islands: A Reappraisal". American Journal of Archaeology, 96. 599615.

NIEMAYER, H.G., Ed. (1982a): Phonizier im Westen. Madrider Beitrage, 8. Mainz.

NIEMAYER, H.G. (1982b): "Die phönizische Niederlassung Toscanos: eine Zwischenbilanz". En H.G. Niemeyer (Ed.) Phonizier im Westen. Madrider Beitrage, 8. Mainz, 185-206.

OLAVARRI, E. (1973): "Diferencias en la ceramica de Israel y de Judá en el período de la Monarquía Dividida (c. 930-587 a.C.)". Trabajos de Prehistoria, 30. 120-150.

PELLICER CATALÁN, M. (1962): "Excavaciones en la necrópolis púnica Laurita del Cerro de San Cristóbal (Almuñécar, Granada)". Excavaciones Arqueológicas en España, 17. M.E.C., Madrid.

-(2007): "La Necrópolis Laurita (Almuñécar, Granada) en el contexto de la colonización fenicia". Cuadernos de Arqueología Mediterránea, 17. Universidad Pompeu Fabra. Barcelona.

PLICHT, J. van der, BRUINS, H.J. y NIJBOER, A.J. (2009): "The Iron Age around the Mediterranean: A High Crholology Perspective from the Groningen Radiocarbon Database". Radiocarbon 51, Nr. 1. 213-242.

PRITCHARD, J.S. (1983): "Sarepta and Phoenician culture in the West". Act. I Cong. Int. di Studi Fenici e Punici. Roma, 521-525.
-(1988): Sarepta IV. The Objects from Area II, X. The University Museum of the University of Pennsylvania Excavations at Sarafand, Lebanon (Publications de l'Université Libanaise. Section des Études Archéologiques, II), Beyrouth.

PULAK, C. (1998), "The Uluburun shipwreck, an overview", The International Journal of Nautical Archaeology, 27/3, 188-224.

RAWLINSON, G. (1889): History of Phoenicia. Oxford.

RÖLLIG, W. (1983): "On the Origin of the Phoenicians". Berytus, 31. 79-93.

-(1995): "Phoenician and the Phoenicians in the Context of the Ancient Near East". I Fenici: ieri, oggi, domani. Accademia Nazionale dei Lincei, Commissione per gli studi Fenici e Punici. Roma, 203-214.

RUIZ MATA, D. (1986): “Aportación al análisis de los inicios de la presencia fenicia en Andalucía Sudoccidental, según las excavaciones del Cabezo de San Pedro (Huelva), S. Bartolomé (Almonte, Huelva), Castillo de Doña Blanca (Puerto de Santa María, Cádiz) y El Carambolo (Camas, Sevilla)”. Homenaje a Luis Siret. Cuevas de Almanzora 1984. Sevilla, 537-556.

-(1999): "Visión actual de la fundación de Gadir en la bahía gaditana. El Castillo de Doña Blanca en El Puerto de Santa María y la ciudad de Cádiz. Contrastación textual y arqueológica". Revista de Historia de El Puerto, 21. 11-87.

RUIZ MATA, D. y PÉREZ PÉREZ, C. (1995): El poblado fenicio del Castillo de Doña Blanca (El Puerto de Santas María, Cádiz). Cádiz.

RUIZ MATA, D. y GÓMEZ TOSCANO, F. (2008): "El final de la Edad del Bronce en el Suroeste Ibérico y los inicios de la colonización fenicia en Occidente". En S. Celestino, N. Rafel, y X.L. Armada (Eds.) Contacto cultural entre el Mediterráneo y el Atlántico (siglos XII-VIII ane). La precolonización a debate. Serie Arqueológica - II. Escuela Española de Historia y Arqueología de Roma, CSIC. Madrid, 323-353. 
SAIDAH, R. (1966): "Fuilles de Khalde: Rapport Preliminaire sur la premiere et deuxieme campagnes (1961-1962)". Bulletin du Musee de Beyrouth, 19. Beirut, 51-90.

-(1983): "Noveaux elements de datation de la ceramique de l'Age du Fer au Levant". Acts. I Cong. Int. di Studi Fenici e Punici. Roma, 213-216.

SASS, B. (2002): "Wenamun and his Levant 1075 BC or 925 BC?". Egypt and the Levant, 12. 247-255. Ägypten und Levante, $\mathrm{n}^{\mathrm{o}} 12$, pp. 247-255.

SCHNIEDEWIND, W.M. (2003): "Jerusalem, the Late Judahite Monarchy, and the Composition of the Biblical Texts". En A.G. Vaughn y A.E. Killebrew (Eds.) Jerusalem in Bible and Archaeology: The First Temple Period. Society of Biblical Literature. 375393.

SCHUBART, H. (1976): "Westphönozische teller". Rivista di Studi Fenici 4 (2). 179-196.

-(1982a): "Phönizisch Niederlassungen an der Iberischen Südküste". En H.G. Niemayer (Ed.) Phonizier im Westen. Madrider Beiträge, 8. Maguncia, 207-231.

-(1982b): "Asentamientos fenicios en la costa meridional de la Península Ibérica". Primera Jornadas Arqueológicas sobre Colonizaciones Orientales. Huelva 1980. Huelva Arqueológica, VI. 71-99.

-(2005): "Platos fenicios en Occidente". Lvcentvm XXI-XXII. 45-61.

SCHUBART, H. y ARTEAGA, O. (1986): "El mundo de las colonias fenicias occidentales". Homenaje a Luis Siret. Cuevas de Almanzora 1984. Sevilla, 449-521.

SHARON, I. y GILBOA, A. (2013): "The $S K L$ Town: Dor in the Early Iron Age". En A.E. Killebrew y G. Lehmann (Eds.) The Philistines and other "Sea Peoples" in Text and Archaeology. Society of Biblical Literature, Atlanta, Georgia, 393-468.

SHERRATT, S. (1998): "Sea Peoples" and the Economic Structure of the Late Second Millenium in the Eastern Mediterranean". En S. Gitin, A. Mazar y E. Stern (Eds.) Mediterranean Peoples in Transition. Thirteenth to Early Tenth Centuries BCE”. Jerusalén, 292-313.
SPARKS, K.L. (1998): Ethnicity and Identity in Ancient Israel: Prolegomena to the Study of Ethnic Sentiments and Their Expression in the Hebrew Bible. Kenton L. Sparks. Eisenbrauns.

STAMPOLIDIS, N. C. (2003): "A summary glance at the Mediterranean in the early Iron Age ( $11^{\text {th }}-6^{\text {th }}$ c. BC). En N. Chr. Stampolidis (Ed.) Sea Routes...From Sidon to Huelva. Interconnectios in the Mediterranean (16th6 th c. BC). Cultural Olympiad. Atenas, 4179.

STERN, E. (1978): "Excavations at Tel Mevorak (1973-1976) Part one: From the Iron Age to the Roman period". Qedem, 9. Monographs of the Institute of Archaeology. The Hebrew University of Jerusalem.

-(1990): "New evidence from Dor for the first appearance of the Phoenicians along the northern coast of Israel". Bulletin of the American School of Oriental Research, 279. 27-33.

STEINER, M. (2003): "The Evidence from Kenyon's Excavations in Jerusalem: A Response Essay". En A.G. Vaughn y A.E. Killebrew (Eds.) Jerusalem in Bible and Archaeology: The First Temple Period. Society of Biblical Literature. 347-363.

STIEGLITZ, R.R. (1990): "The Geopolitics of the Phoenician Littoral in the Early Iron Age". Bulletin of the American Schools of Oriental Research, 279. 9-12.

STOS-GALE, Z.A. y GALE, N.H. (2010): "Bronze Age metal artefacts found on Cyprus - Metal from Anatolia and the Western Mediterranean". Trabajos de Prehistoria 67, N. ${ }^{\circ} 2,389-403$.

TÄCKHOLM, U. (1969): "El concepto de Tarschich en el Antiguo Testamento y sus problemas". En J. Maluquer de Motes (Ed.) Tartessos y sus problemas. V Symposium internacional de Prehistoria Peninsular. Barcelona, 79-90.

TARRADELL, M. (1956): "Las excavaciones de Lixus y su aportación a la cronología de los inicios de la expansión fenicia-cartaginesa en el Extremo Occidente". Actas de la IV Sesión de los Congresos Internacionales de Ciencias Prehistóricas y Protohistóricas. Madrid 1954. Zaragoza, 789-796. 
-(1967): "Los fenicios en Occidente. Nuevas perspectivas". En D. Harden: Los Fenicios. Barcelona, 277-314.

TORRES ORTIZ, M. (2008): “The Chronology of the Late Bronze Age in Western Iberia and the Beginning of the Phoenician Colonization in the Western Mediterranean". En D. Brandherm y M. Trachsel (Eds.) A New Dawn for the Dark Age? Shifting Paradigms in Mediterranean Iron Age Chronology. International Union for Prehistoric and Protohistoric Sciences. Proceedings of the XV World Congress (Lisbon, 4-9 September 2006), vol. 9, Sec. C35. BAR International Series 1871. 135147.

-(2012): "La Precolonización en Extremadura". En J. Jiménez Ávila (Ed.) Sidereum Ana II. El río Guadiana en el Bronce Final. Anejos de AEspA LXII. Mérida (Badajoz), 355-474.

TSIRKIN, J.B. (2001): "Canaan. Phoenicia. Sidon”. Aula Orientalis 19. 271-279.

TUSA, V. (1973): "La Statuetta fenicia del Museo Nazionale di Palermo". Rivista di Studi Fenici, 1. 173-179.

USSISHKIN, D. (2007): "Archaeology of the Biblical Period: On some Questions of Methodology and Chronology of the Iron Age". Proceedings of the British Academy, 143.131-141.

-(2012): “On Nehemiah's City Wall and the Size of Jerusalem during the Persian Period: An Archaeologist's View". En I. Kalimi (Ed.) New Perspectives on Ezra-Nehemiah. History and Historiography, Text, Literature, and Interpretation. Eisenbrauns. Winona Lake, Indiana. 101-130.

VAUGHN, A.G. y KILLEBREW, A.E., Eds. (2003): Jerusalem in Bible and Archaeology: the First Temple period. Society of Biblical Literature Symposium Series, 18. Atlanta.

VILAÇA, R. (2006): “Artefactos de ferro em contextos do Bronze Final do Território português: Novos contributos e reavaliação dos dados". Complutum, 17, 81-101.

-(2008): "Reflexões em torno da «presença mediterrânea» no Centro do território português, na charneira do Bronze para o Ferro". En S. Celestino, N. Rafel y X.L. Armada (Eds)
Contacto cultural entre el Mediterráneo y el Atlántico (siglos XII-VIII ane). La Precolonización a debate. Madrid, 371-400.

-(2013a): L'arrivée des premiers fers dans l'Occident atlantique". En L. Callegarin y A. Gorgues (Coords.) Les transferts de technologie au premier millénaire av. J.C. dans le sud-ouest de l'Europe. Mélanges de la Casa de Velázquez. Nouvelle série, 43 (1). 39-64.

-(2013b): "Contextes d'utilisation, de circulation et de déposition des premiers artefacts en fer de l'Atlantique occidental". En A. Colin y F. Verdin (Dirs.) L'âge du Fer en Aquitaine et sur ses marges. Mobilité des hommes, diffusion des idées, circulation des biens dans l'espace européen à l'âge du Fer. Actes du $35^{\mathrm{e}}$ Colloque international de l'AFEAF (Bordeaux, 2-5 juin 2011). Burdeos, 631-642.

VOSKOS, I. y KNAPP, B. (2008): "Cyprus at the End of the Late Bronze Age: Crisis and Colonization or Continuity and Hybridization?". American Journal of Archaeology, 112. 659-684.

WAGNER, C.G. y ALVAR, J. (1989): "Fenicios en Occidente: la colonización agrícola". $R S F$, XVII. 61-102.

WARD, W.A. y JOUKOWSKY, M.S., Eds. (1992): The Crisis Years: The 12th Century B.C. From Beyond the Danube to the Tigris. Dubuque IA.

WATSON-TREUMANN, B. (2001): "Beyond the Cedars of Lebanon. Phoenician Timber Merchants and Trees from the 'Black Mountain"”. Die Welt des Orients, Bd. 31. 75-83.

WHITTAKER, C.R. (1974): "The Western Phoenicians: Colonisation and Assimilation". PCPhS 200, XX. 58-79.

YADIN, Y. (1958): "Solomon's City Wall and Gate at Gezer". IEJ, 8. 80-86.

YADIN, Y. y BEN-TOR, A. (1993): "Hazor". En E. Stern (Ed.) The New Encyclopedia of Archaeological Excavations in the Holy Land, vol. 2, Israel Exploration Society \& Carta, Jerusalén, 595.

YADIN, Y., AHARONI, Y., AMIRAN, R., DOTHAN, T., DUNAYEVSKY, I. y PERROT, J. (1960): Hazor II: an account of the Second season of excavations, 1956, Jerusalén. 
YON, M. (1992): "The End of the Kingdom of Ugarit". En W.A. Ward y M.S. Joukowsky (Eds.) The Crisis Years: The 12th Century B.C. From Beyond the Danube to the Tigris. Dubuque IA, 111-122.
ZACCAGNINI, C. (1990): "The Transition from Bronze to Iron in the Near East and in the Levant: Marginal Notes". Journal of the American Oriental Society, Vol. 110, No. 3. 490-502.

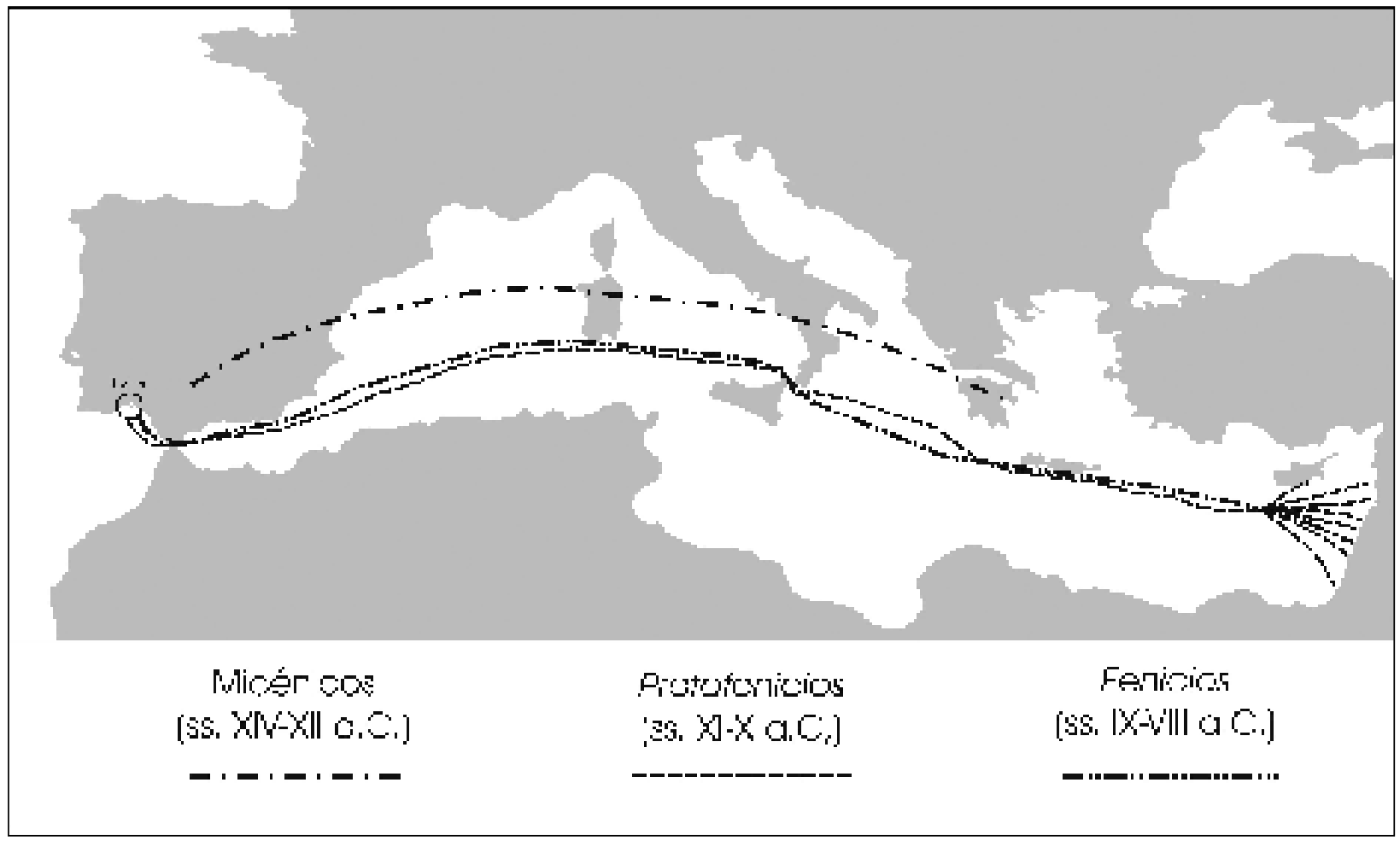

